\title{
A new multicopter-based unmanned aerial system for pollen and spores collection in the atmospheric boundary layer
}

\author{
Claudio Crazzolara ${ }^{1,2}$, Martin Ebner ${ }^{1}$, Andreas Platis ${ }^{1,2}$, Tatiana Miranda ${ }^{1,3}$, Jens Bange ${ }^{1,2}$, and Annett Junginger ${ }^{1,3}$ \\ ${ }^{1}$ Department for Geosciences, Eberhard-Karls-Universität Tübingen, 72074 Tübingen, Germany \\ ${ }^{2}$ Center for Applied Geoscience, Eberhard-Karls-Universität Tübingen, 72074 Tübingen, Germany \\ ${ }^{3}$ Senckenberg Centre for Human Evolution and Paleoenvironment (S-HEP-Tübingen), 72074 Tübingen, Germany
}

Correspondence: Claudio Crazzolara (claudio.crazzolara@uni-tuebingen.de)

Received: 10 September 2018 - Discussion started: 12 October 2018

Revised: 15 February 2019 - Accepted: 24 February 2019 - Published: 12 March 2019

\begin{abstract}
The application of a new particle collection system (PCS) developed in-house and operated on board a commercially available multicopter unmanned aerial vehicle (UAV) is presented as a new unmanned aerial system (UAS) approach for in situ measurement of the concentration of aerosol particles such as pollen grains and spores in the atmospheric boundary layer (ABL). A newly developed impactor is used for high-efficiency particle extraction on board the multicopter UAV. An airflow volume of $0.2 \mathrm{~m}^{3} \mathrm{~min}^{-1}$ through the impactor is provided by a batterypowered blower and measured with an on-board mass flow sensor. A bell-mouth-shaped air inlet of the PCS is arranged and oriented on the multicopter UAV to provide substantial isokinetic sampling conditions by advantageously using the airflow pattern generated by the propellers of the multicopter UAV.

More than 30 aerosol particle collection flights were carried out near Tübingen in March 2017 at altitudes of up to $300 \mathrm{~m}$ above ground level (a.g.l.), each with a sampled air volume of $2 \mathrm{~m}^{3}$. Pollen grains and spores of various genera, as well as large $(>20 \mu \mathrm{m})$ opaque particles and fine dust particles, were collected, and specific concentrations of up to 100 particles per $\mathrm{m}^{3}$ were determined by visual microscopic analysis. The pollen concentration values measured with the new UAS match well with the pollen concentration data published by the Stiftung Deutscher Polleninformationsdienst (PID) and by MeteoSwiss. A major advantage of the new multicopter-based UAS is the possibility of the identification of collected aerosol particles and the measurement of their concentration with high temporal and spatial resolu-
\end{abstract}

tions, which can be used inter alia to improve the database for modelling the propagation of aerosol particles in the ABL.

\section{Introduction}

In situ measurements of the concentration of aerosol particles such as pollen, spores, and fine particulate matter in the atmospheric boundary layer (ABL) are of great interest in numerous scientific disciplines (Hardin and Hardin, 2010).

For example, in agricultural science, the concentration and aerial dispersal of pollen and spores are of interest with regard to an optimization of yield (Aylor, 2005), the spread of plant diseases (Aylor et al., 2011), and also with regard to the spread of transgenetic material originating from genetically manipulated corn (Hofmann et al., 2013). In particular, plant pathogens are able to travel hundreds or even thousands of kilometres through the atmosphere from their origin to the place where they cause damage (Schmale III and Ross, 2015). The travel distance, but also the concentration of pollen, is dependent on the seasonal atmospheric convective conditions (Boehm et al., 2008). For example, seasonal variations have been reported for fungal spores of the genus Fusarium (Lin et al., 2014) with distributions at altitudes of 40 to $320 \mathrm{~m}$ above ground level (a.g.l.) as reported by Schmale et al. (2012) using an unmanned aerial vehicle.

In meteorology, it is known that mineral dust particles that originated from Saharan dust storms and were transported, for example, to southern Florida effectively act as ice nuclei capable of glaciating supercooled altocumulus clouds (Sassen et al., 2003). Pollen grains, although only moder- 
ately hygroscopic, are able to act as cloud condensation nuclei and exhibit a bulk uptake of water under subsaturated conditions (Pope, 2010). Investigations on the hygroscopic growth of pollen suggest that extreme pollen concentrations $\left(>1000 \mathrm{~m}^{-3}\right)$ may interfere with the activation of the background sulfate aerosol mode in pristine environments (Griffiths et al., 2012). Spores, millions of tons of which are dispersed into the atmosphere every year, may also act as nuclei for the condensation of water in clouds (Hassett et al., 2015). It is also suggested that some atmospheric microbes could catalyse the freezing of water at higher temperatures and may facilitate the onset of precipitation (Jimenez-Sanchez et al., 2018). Thus, knowledge about the spatial distribution and transportation distances of dust particles, pollen, spores, and microbes would allow the determination of their contribution in cloud formation processes, which influence not only local weather, but also the regional or even global climate. Meteorological processes have a great influence on the propagation behaviour of the aerosol particles in the ABL. For in situ measurements of relevant meteorological parameters in the ABL, e.g. the air temperature with high temporal resolution, a remotely piloted fixed-wing unmanned aerial vehicle (UAV) can be used (Wildmann et al., 2013). Also, the use of a multicopter UAV with on-board temperature, humidity, and gas sensors for in situ measurements of meteorological variables in the ABL was reported recently (Brosy et al., 2017).

In human medicine, the careful scientific evaluation of the actual concentration of pollen in the air is an indispensable basis for reliable pollen risk information. Inadequate forecasts concerning the expected pollen concentration are regarded as a considerable health risk for pollen allergy sufferers (Bastl et al., 2017). Damialis et al. (2017) just recently reported the first basic experiments measuring pollen concentrations at considerable altitudes above ground level by using a manned aircraft. However, this research has shown that the use of a manned aircraft in densely populated areas is limited and further requires considerable organizational and financial effort.

In environmental sciences, the pollution of air with fine particulate matter has been a problem for many years, in particular in urban areas with unfavourable geographical topography. The $\mathrm{PM}_{2.5}$ and $\mathrm{PM}_{10}$ particulate matter according to the National Ambient Air Quality Standards for particulate matter of the U.S. Environmental Protection Agency (Vincent, 2007), as well as coarse particles, have been chemically characterized by Hueglin et al. (2005). In a simplified view, $\mathrm{PM}_{2.5}$ is the fraction of particulate matter (PM) consisting of inhalable particles having a size of $2.5 \mu \mathrm{m}$ and smaller, whereas $\mathrm{PM}_{10}$ is the fraction of particulate matter (PM) consisting of inhalable particles having a size of $10 \mu \mathrm{m}$ and smaller. Accordingly, $\mathrm{PM}_{2.5}$ is incorporated in $\mathrm{PM}_{10}$. The samples were taken using pre-weighed quartz fibre filters, which were weighed again after collection of particles. This method requires considerable expenditure and processing time in particular for pre- and reconditioning of the fil- ters prior to the respective weighing step. The possibility of assigning health risks to specific classes of particulate matter has been investigated, but the results are not satisfactorily reliable yet (Harrison and Yin, 2000), not least because of the scarcity of measurement data, which are, in turn, related to the complex measuring methods. Further areas of greater interest in particle concentration in the air are the scientific fields of palaeo-environmental and palaeo-climatological reconstructions. Here, for example, the knowledge of the spatial and temporal distribution of pollen could help to gain insights in their genus-specific propagation behaviour and possible transport distances. This would enable us to improve the accuracy of paleoclimate models derived from pollen grains extracted from lacustrine or marine sediments (Shang et al., 2009).

For most of these applications, it would be highly desirable not only to count the number or measure the size of the particles as done with an optical particle counter (OPC), but also to identify the particles according to their type and/or chemical composition. In this regard, particle collection with subsequent particle-type identification and quantification has an advantage over particle counting, at least as long as reliable in situ particle identification is not available. First attempts to collect bioaerosol particles using a pollen trap mounted on a fixed-wing UAV are described in Gottwald and Tedders (1985). Another way to realize the collection of airborne particles is to use a tethered balloon with rotating rods for capturing airborne pollen grains (Comtois et al., 2000). Since the balloon experiences wind drift, the possibilities of performing measurements at a predetermined position are limited. In addition, the air volume sampled by the rotating rods is determinable with limited accuracy only. Sticky surfaces carried by a fixed-wing autonomous UAV described by Schmale III et al. (2008) and Aylor et al. (2011) allow long-range particle collection but provide only limited spatial resolution of particle concentration values. The sampled air volume, again, is determinable with limited accuracy only. In addition, the requirement of a runway for start and landing limits the potential use of fixed-wing UAVs in urban or built-up areas.

Here we present the structural design and first application of a new particle collection system (PCS) developed in-house and operated on board a commercially available multicopter UAV (Fig. 1) for in situ measurements of the concentration of pollen and spores in the ABL. Initially, a commercially available multicopter UAV that meets the requirements for payload capability as well as flight stability and reliability was selected and built from a kit. The multicopter UAV provides not only the possibility of vertical take-off and landing, thus simplifying the application in urban areas, but - even more importantly - also the possibility of hovering and hence collecting particles at elevated positions that can be maintained with high precision. Then, experiments were conducted to investigate the airflow pattern created by the UAV's propellers during hovering. The experimental results were used to determine the dimension and position of the air inlet of the PCS 


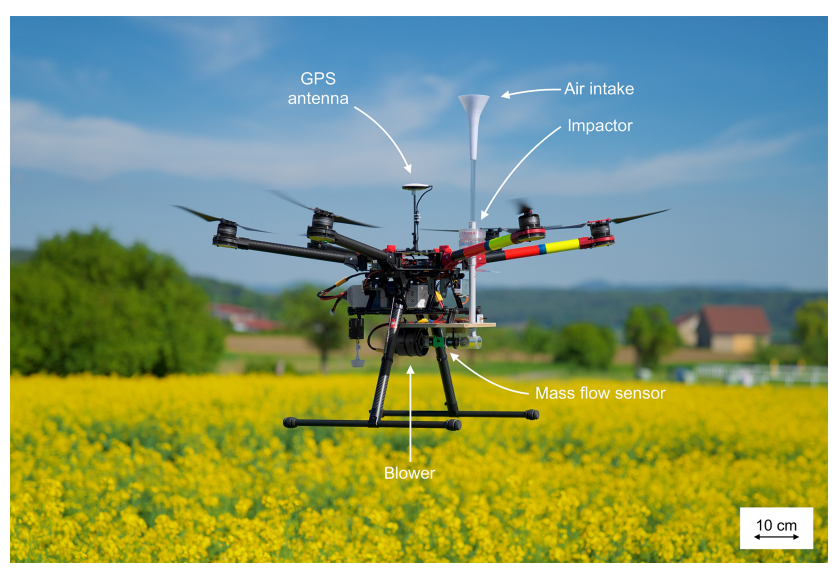

Figure 1. Multicopter UAV (DJI S900) in hovering flight with components of the particle collection system as indicated: air inlet, impactor, mass flow sensor, and blower. The inlet is arranged about $30 \mathrm{~cm}$ above the propeller plane.

on the multicopter UAV in order to provide substantial isokinetic sampling conditions.

An essential part of the present study was the development of a new PCS that can be operated on board the multicopter UAV despite the weight and power constraints. One major goal in the development of the PCS was to sample an air volume of $1 \mathrm{~m}^{3}$ within $5 \mathrm{~min}$ in order to ensure a statistically evaluable number of collected particles, even in the case of low particle concentrations in the air, and also to provide a high temporal resolution of the measurement results compared to other particle collection systems. This goal was achieved by using a powerful blower that delivers a typical airflow volume of $0.2 \mathrm{~m}^{3} \mathrm{~min}^{-1}$ (corresponding to 200000 standard cubic centimetres per minute $-200000 \mathrm{sccm}$ ) through the PCS. Another challenge was to develop an impactor that ensures reliable separation of the aerosol particles even at these high airflow rates.

In order to determine the capability of the PCS operated on board the multicopter UAV and to test the reliability of the entire new unmanned aerial system (UAS), several test flights were conducted at different altitudes over several days in March 2017. The collected particles were analysed and counted using light microscopy. Finally, the pollen concentration values determined with the PCS on board the multicopter UAV were compared with corresponding data published by forecast information services such as the Stiftung Deutscher Polleninformationsdienst (PID) or MeteoSwiss.

\section{Development of a system for aerial particle collection}

\subsection{Multicopter unmanned aerial vehicle (UAV)}

A DJI S900 hexacopter, commercially available from the Chinese company DJI Technology Co. Ltd, was selected as multicopter UAV with regard to flight performance, payload capabilities, and expansion options. The DJI S900 has a diagonal wheelbase of $900 \mathrm{~mm}$ and a maximum take-off weight of $8.2 \mathrm{~kg}$. Propeller arms and propellers are foldable, which allows a space saving and comfortable transport and fast setup time of less than $10 \mathrm{~min}$ at the site of operation, including the set-up of the PCS. At ambient air temperatures between -5 and $+37^{\circ} \mathrm{C}$ as experienced during tens of flight operations in 2017 , the DJI S900 worked reliably (i.e. not a single flight interruption occurred due to technical problems) and it was robust (i.e. the components withstood all applied stresses without any problems or hardware failure).

A DJI A2 flight control system was employed to automatically control the flight attitude, i.e. roll, pitch, and yaw angles as well as the flight altitude, and to maintain the spatial position of the multicopter UAV using a GPS receiver. A remote control of the type T14SG $(2.4 \mathrm{GHz}$ band, 14 control channels) by Futaba Corporation was chosen due to its high reliability over long distances. Telemetry data such as battery parameters (voltage, current, and capacity) and the barometrically determined flight altitude above ground level were retransmitted from the remote-control receiver on board the multicopter UAV to the handheld transmitter on the ground.

The DJI S900 was operated with a 6-cell Lithium polymer battery (LiPo, 22.2 V, $12000 \mathrm{mAh}, 266 \mathrm{Wh}$ ). During regular flight operations, preferably only $80 \%$ of the nominal capacity was taken from the battery in order to have safety reserves in case of unexpected flight manoeuvres and to increase the durability of the LiPo battery. The fully equipped multicopter UAV, including the mounted PCS, has a take-off weight of $6.5 \mathrm{~kg}$. The possible flight time is dependent on several factors, including the altitude above sea level (a.s.l.) of the launch site, the prevailing wind conditions, and the altitude above ground level during particle collection operation. For our aerosol particle collection flights, starting from a launch site $400 \mathrm{~m}$ a.s.l. with side winds on the ground of about $2 \mathrm{~m} \mathrm{~s}^{-1}$, typical flight times were $15 \mathrm{~min}$, including a 10 min aerosol particle collection operation at an altitude of $300 \mathrm{~m}$ a.g.l., while the remaining battery capacity was typically $30 \%$.

\subsection{The set-up of the new particle collection system (PCS)}

A new PCS was developed in order to meet the requirements for aerial use on board a multicopter UAV. To ensure a number of at least 10 collected particles, even in the case of a particle concentration in the sampled air being as low as 5 particles per $\mathrm{m}^{3}$, an air volume of $2 \mathrm{~m}^{3}$ has to be sampled. With regard to the limited maximum flight time of the multicopter UAV, $10 \mathrm{~min}$ are typically available for airborne particle collection operation. Accordingly, the PCS has to be able to process an airflow volume of $0.2 \mathrm{~m}^{3} \mathrm{~min}^{-1}$.

Starting from these boundary conditions, an impactorbased PCS was developed (Fig. 2) that comprises (1) an air inlet that allows the intake of ambient air under near- 


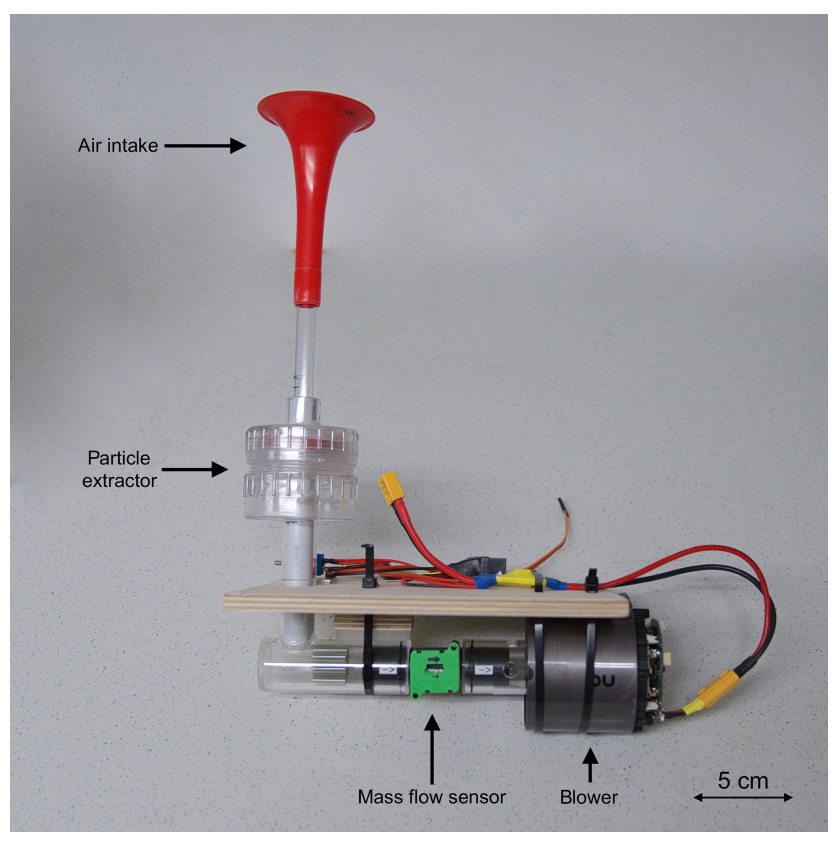

Figure 2. Newly developed particle collection system (PCS) with a complete weight of $600 \mathrm{~g}$ comprising (1) an air inlet that allows the intake of ambient air under near-isokinetic conditions, (2) an impactor for extracting the particles from sampled air and depositing them on a sample carrier, (3) a mass flow sensor located downstream of the particle extractor, measuring the air mass flow through the PCS, and (4) an electric blower generating the airflow through the components of the PCS. The components of the PCS and their connections are airtight. Air volume flow during operation is $200 \mathrm{~L} \mathrm{~min}^{-1}$.

isokinetic conditions, (2) an impactor for extracting the particles from sampled air and depositing them on a sample carrier, (3) a mass flow sensor, located downstream of the particle extractor, measuring the air mass flow through the PCS, and (4) an electric blower generating the airflow through the components of the PCS independent of the airspeed of the multicopter UAV. The components of the PCS and their connections are airtight, which means that the air volume passing the mass flow sensor is the same as that flowing through the particle extractor and the same as the air volume taken in at the inlet.

\subsubsection{Bell-mouth-shaped air inlet}

The geometry and orientation of the air inlet must be chosen in such a way that the sampled air is representative in terms of its particle load, which can be achieved by isokinetic sampling (Kulkarni et al., 2011). Isokinetic sampling means that the flow velocity of the air entering the inlet is identical, by magnitude and direction, to the flow velocity of the ambient air approaching the inlet. If isokinetic sampling is not ensured, effects based on the aerodynamic behaviour of aerosol particles, such as their mass inertia and coefficient of drag $c_{\mathrm{d}}$, can result in particle uptake of the ambient air that is not representative and leads to a falsification of the measured particle concentration value. The larger the particles are and the more mass and thus inertia they have, the more important isokinetic sampling becomes (Kulkarni et al., 2011).

In order to provide omnidirectional air intake under isokinetic or at least near-isokinetic conditions, a bell mouth was chosen, with a wide end for the air inlet and a narrow end for the connection to the subsequent particle extraction unit (Fig. 2). The substantially hyperbolic form continuously accelerates the air that is drawn in. While the velocity of the air entering the inlet at the wide end is typically 1 to $3 \mathrm{~m} \mathrm{~s}^{-1}$, the air is accelerated to a mean velocity of $50 \mathrm{~m} \mathrm{~s}^{-1}$ at the narrow end.

\subsubsection{Impactor as particle extraction unit}

Operation on a multicopter UAV requires a particle extraction unit that has a low mass and provides a high particle extraction rate, even at large airflow volumes $\left(0.2 \mathrm{~m}^{3} \mathrm{~min}^{-1}\right)$, in order to allow short $(10 \mathrm{~min})$ sampling operation periods. Additionally, in order to achieve a lean workflow from sampling to visual particle identification and counting, the extracted particles should be easily accessible for visual analysis without complex and time-consuming sample preparation steps. In this context "lean workflow" also means that preferably an initial estimate of the quantity and type of particles collected should already be possible in the field by visual inspection with simple tools such as a magnifying glass; this allows, if necessary, an adjustment of the flight altitude or the sampling operation period during the immediately following particle collection flight. A device that has the potential to meet all these demands is based on an impactor.

The functional principle of an impactor is based on the deflection of a particle-loaded free-flow gas stream by means of an impaction plate (Kulkarni et al., 2011). The gas stream is usually accelerated through a nozzle up to a velocity that depends on the volume flow and nozzle geometry. An impaction plate coated with an adhesive film is arranged in the open jet at a small distance from the nozzle that forces the particle-loaded gas stream to deflect. Due to their mass inertia, the particles in the gas stream are able to follow this deflection only to a limited extent. As a consequence, particles with a sufficiently high mass inertia impinge on the surface of the impaction plate and are retained on the adhesive film. Hirst (1952) first described the application of an impactorbased device for extracting aerosol particles such as spores, but only for stationary use and sampling of a very low airflow volume of about $10 \mathrm{~L} \mathrm{~min}^{-1}$.

In order to sample an air volume of $2 \mathrm{~m}^{3}$ within an aerial sampling operation period of $10 \mathrm{~min}$, a sampled airflow volume of $0.2 \mathrm{~m}^{3}(200 \mathrm{~L})$ per minute is required. The orifice of the impactor was chosen to be circular with a diameter of $9 \mathrm{~mm}$, corresponding to an orifice area of about $64 \mathrm{~mm}^{2}$. Thus, for an airflow volume of $0.2 \mathrm{~m}^{3} \mathrm{~min}^{-1}$, the mean ve- 
locity of the open jet in the orifice area is about $50 \mathrm{~m} \mathrm{~s}^{-1}$. This mean velocity $v$ through the orifice area can be calculated from the volume flow $Q$ and the area $A$ by

$v=Q / A$.

Figure 3 shows a longitudinal cut through the newly developed impactor of the PCS. A commercially available $50 \mathrm{~mm}$ diameter filter housing from Sartorius AG was used with modifications to form the case of the impactor. The housing comprises two injection-moulded halves of transparent polycarbonate (PC) forming an upper and a lower part that can be screwed together. Into a central bore of the upper part of the filter housing, the lower end of a first transparent polymethyl methacrylate (PMMA) cylindrical pipe with an inner diameter of $9 \mathrm{~mm}$ was inserted. The upper end of the first pipe will be connected to the bell mouth. Into a central bore of the lower part of the filter housing, the upper end of a second PMMA cylindrical pipe with an inner diameter of $16 \mathrm{~mm}$ was inserted; the lower end of the second pipe will be connected to the mass flow sensor as described in the following section. In between the two housing halves, a particle sample carrier acting as the impaction plate was installed opposite the lower end of the first cylindrical pipe.

The particle sample carrier is $43.5 \times 26 \mathrm{~mm}$ in size and $1 \mathrm{~mm}$ thick and can be cut from a conventional microscopic glass slide. An adhesive film of glycerine gelatine was applied onto the glass slide in order to retain the impinged particles. Details on slide preparation are described in Sect. 2.3. The sample carrier rests in the lower housing part on a circular ring-shaped surface (Fig. 3). When the two housing parts are screwed together, the particle sample carrier is fixed by means of a silicone $\mathrm{O}$ ring, which rests on the sample carrier and is pressed down by the upper housing part as shown in Fig. 3. Figure 4a shows a perspective view of the assembled particle extractor, while Fig. $4 \mathrm{~b}$ shows a perspective view of the particle extractor with the upper housing part removed, and Fig. $4 \mathrm{c}$ shows a top view of the particle extractor with the upper housing part removed and with a particle-loaded sample carrier. The total weight of the impactor, including the upper and lower pipes and the installed particle sample carrier, is about $50 \mathrm{~g}$.

\subsubsection{Mass flow sensor}

A reliable determination of the concentration of aerosol particles requires the precise determination of the sampled air volume. This was achieved by installing a mass flow sensor that permanently remains in the airflow path of the PCS, irrespective of whether data from the flow sensor were collected or not. A SFM 3000-200-C mass flow sensor of the Swiss company Sensirion AG was used for this purpose. This sensor offers a bidirectional measuring span of \pm 200 standard $\mathrm{L} \mathrm{min}^{-1}$ (slm), with standard conditions defined as $20^{\circ} \mathrm{C}$ air temperature and $1013.25 \mathrm{hPa}$, and provides a digital output signal using the $\mathrm{I}^{2} \mathrm{C}$ protocol. The ac-

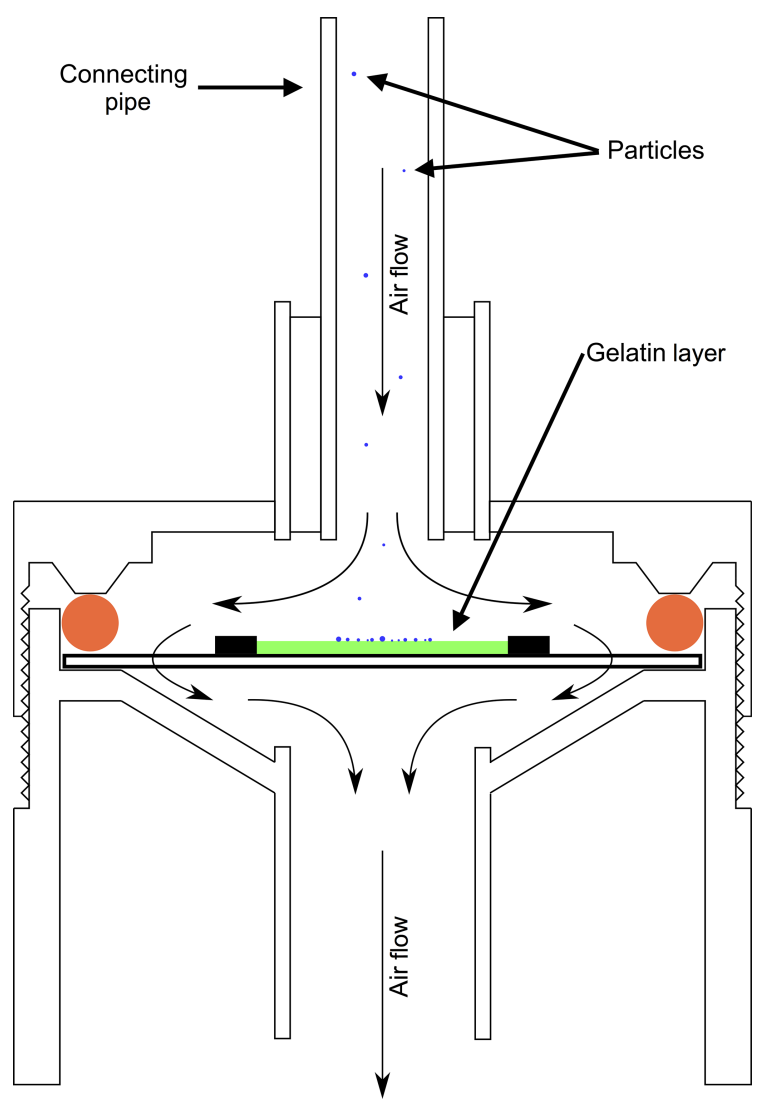

Figure 3. Schematic longitudinal cross section through the impactor used as a particle extractor in the particle collection system. Particles are drawn through the pipe from the top towards the glycerine gelatine-covered microscope slide. Glycerine gelatine is highlighted in green, cross section of silicone $\mathrm{O}$ ring in red. Mean impaction velocity is about $50 \mathrm{~m} \mathrm{~s}^{-1}$.

curacy of the individually calibrated sensor is $1.5 \%$ (typical) and $2.5 \%$ (maximum) of measured value between -20 and $+80^{\circ} \mathrm{C}$, and the update time is $0.5 \mathrm{~ms}$ corresponding to $2000 \mathrm{~Hz}$. The total weight is $18 \mathrm{~g}$ with the dimensions of $100 \mathrm{~mm} \times 20 \mathrm{~mm} \times 30 \mathrm{~mm}$ (length $\times$ width $\times$ height).

\subsubsection{Blower}

The electrically operated blower must ensure a high airflow volume through the PCS during flight operations and the associated power and mass limitations. It is also necessary that the blower performance is substantially independent of fluctuations of the battery voltage in order to provide a constant airflow volume through the PCS. A blower that meets these demands is commercially available in handheld vacuum cleaners of the British company Dyson Ltd. The blower that we used in the PCS has a total weight of $245 \mathrm{~g}$ and can be operated at two power levels, either 100 or $350 \mathrm{~W}$. Due to its integrated microprocessor control, the blower features a very fast spin-up (0.2 s) and spool downtime (1 $\mathrm{s})$, and provides 


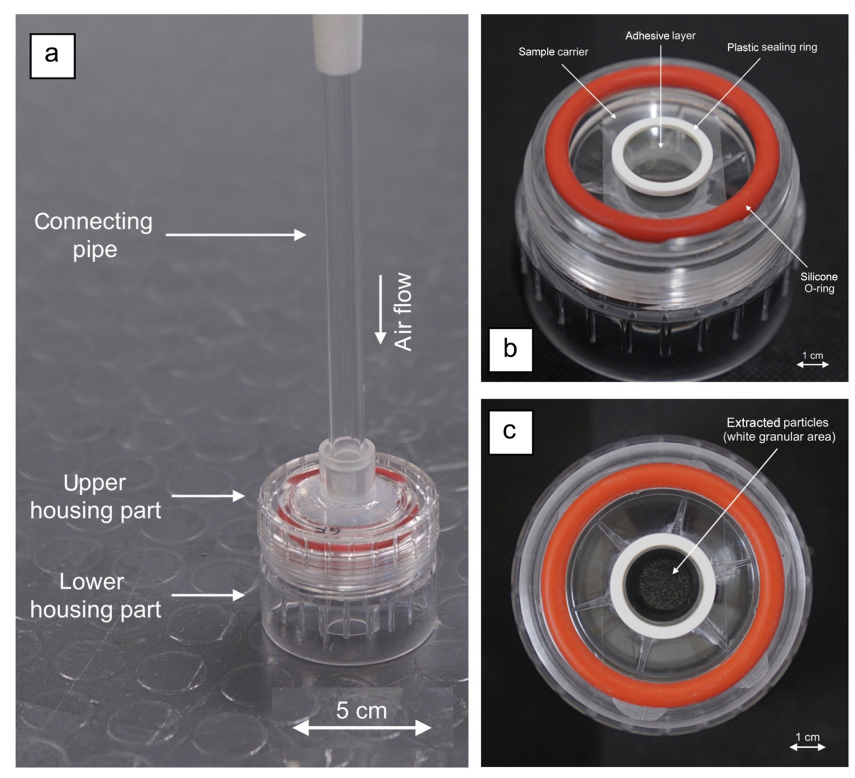

Figure 4. (a) Perspective view of the assembled particle extractor, with a connecting pipe to the bell mouth; (b) perspective view of the particle extractor with the upper housing part removed and the sample carrier installed; (c) top view of the particle extractor with the upper housing part removed and particle-loaded sample carrier; extracted particles are deposited in the area enclosed by the white plastic ring.

constant blower power in a battery voltage range between 20.4 and $25.2 \mathrm{~V}$. An adjustable leak valve is arranged in the connection between mass flow sensor and blower, since the blower offers a considerable surplus already if operated in the lower $100 \mathrm{~W}$ mode. On the ground, the leak valve was adjusted to set the airflow volume to 200 slm by digitally reading out the mass flow sensor. As regularly performed control measurements have shown, this setting is very stable over many measurement flights. One channel of the remote control system was used to switch the blower on and off when the multicopter UAV was airborne and the particle collection position was reached, i.e. the desired altitude above ground level. As long as the blower was switched on, i.e. as long as particle collection was performed, the multicopter UAV was maintained (by hovering) in this desired particle collection position. Before leaving this position, the blower was remotely switched off, thus terminating the particle collection operation. The value of the electrical current, drawn by the blower from the battery, was measured on board the multicopter UAV and transmitted to and monitored on the ground so that it was known whether the blower really went into operation (switched on) or was really out of operation (switched off).

\subsection{Preparation and handling of sample carriers}

An individual particle sample carrier was used for each particle collection operation (Fig. 5a). Accordingly, after each particle collection operation, the sample carrier was removed from the impactor and replaced by a new one. The particle sample carrier consists of a common microscope glass slide with a size of $43.5 \mathrm{~mm}$ by $26 \mathrm{~mm}$. An adhesive layer of glycerine gelatine (Morphisto Evolutionsforschung und Anwendung $\mathrm{GmbH}$, Frankfurt, Germany) was applied circularly to the surface of the glass plate facing towards the open jet, allowing the aerosol particles to penetrate the sticky surface. In order to define and limit the lateral extent of the gelatine layer, a circular sealing ring made of polyamide (PA) with inner and outer diameters of 17 and $22 \mathrm{~mm}$, a thickness of $1.5 \mathrm{~mm}$ and a rectangular cross section was arranged centrally on the glass plate. The glycerine gelatine was heated in a water bath at $45^{\circ} \mathrm{C}$ and poured onto the glass plate into the circular area delimited by the polyamide sealing ring.

The sample carriers were produced in batches, usually a few days prior to the scheduled particle sampling operation, while the production date of the batches is being recorded. Production, handling, and storage of the sample carriers were performed in a portable laminar airflow box under continuous flow of filtered air. The air was filtered by two pre-filters and finally a H14-specified HEPA (high-efficiency particulate air) filter removing more than $99.995 \%$ of the particles in the most critical size range of 0.1 to $0.3 \mu \mathrm{m}$. Small containers of transparent plastic were used for individually transporting and storing the particle sample carriers prior and post-particle sampling operation. Repeated inspections proved that these measures reliably prevent contamination of sample carriers during manufacture, handling, transport, and storage.

Careful post-sampling treatment is highly necessary to avoid contamination and allow preservation. Immediately after landing the multicopter UAV, the particle-loaded sample carrier was carefully removed from the impactor and placed into its transport box (Fig. 5b, step 1). Back in the laminar airflow box in the lab, a protective layer of one drop of liquid gelatine was applied to the particle-loaded gelatine layer (Fig. 5b, step 2) in order to prevent damage to the particle-loaded gelatine layer. A common microscope cover slip $(22 \times 22 \mathrm{~mm}, 0.15 \mathrm{~mm}$ thick) was then placed centrally on the liquid gelatine in order to seal it and protect the sample from contamination (Fig. 5b, step 3). Finally, this cover slip was gently lowered vertically, allowing the liquid gelatine to spread (Fig. 5b, step 4). Special care was taken to avoid air bubbles between the cover slip and the gelatine. 


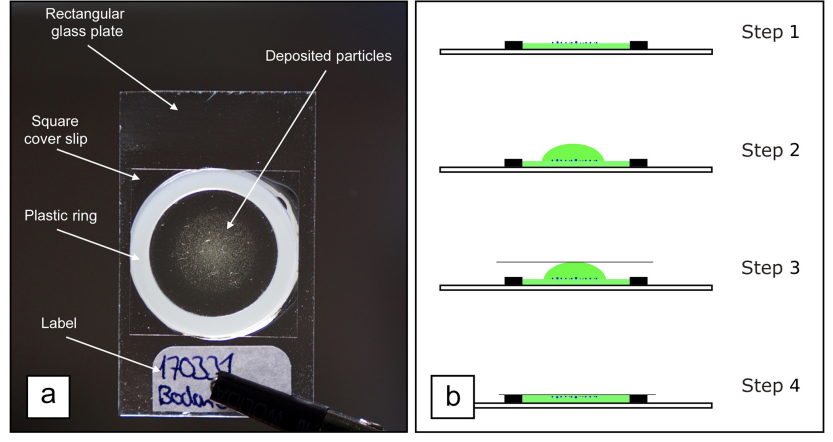

Figure 5. (a) Top view of a particle-loaded sample carrier comprising a common microscope slide and a plastic ring with gelatine used as the particle embedding layer, covered with a transparent microscope cover slip (square). (b) Post-sampling treatment steps 1 to 4 of the particle-loaded sample carrier that avoid contamination and allow preservation are shown as cross sections through a sample carrier. Highlighted in green is a gelatine layer in which the collected particles (blue dots) are embedded. Step 1: sample carrier immediately after particle collection with deposited particles exposed. Step 2: a drop of molten gelatine is placed onto the particle-loaded gelatine layer. Step 3: a cover slip is placed centrally on the drop of liquid gelatine. Step 4: the cover slip is lowered vertically to protect and seal the particle-loaded glycerine gelatine.

\section{Experiments}

\subsection{Multicopter-caused airflow pattern (smoke plume test)}

When using a multicopter UAV for aerosol particle collection, the position of the air intake of the PCS has to be considered. It also needs to be considered how the air intake should be aligned in relation to the airflow generated by the propellers of the multicopter UAV in order to avoid an impairment of the measurement results and to ensure a substantial isokinetic sampling. Haas et al. (2014) used computational fluid dynamics (CFD) calculations for a complete study of the aerodynamics of a multicopter UAV of a similar size and weight to the one used in the presented study. As a result of their CFD calculations, the volume of air mixed by the propellers of the multicopter UAV is approximately a cylinder with a radius of $2 \mathrm{~m}$ and with an extent of $2 \mathrm{~m}$ above and $8 \mathrm{~m}$ below the multicopter UAV. Calculations of the magnitude of air velocity showed high values in the immediate vicinity of the propellers as well as below the propellers, whereas the corresponding values above the propellers are significantly lower. Thus, for the collection of aerosol particles as intended within this study, it was decided to arrange the air intake of the PCS sufficiently above the propellers of the multicopter UAV.

In order to investigate the actual airflow around the multicopter UAV used in this study under ambient conditions with side wind, a visual airflow test was performed in January 2017 at the airfield in Poltringen, Germany
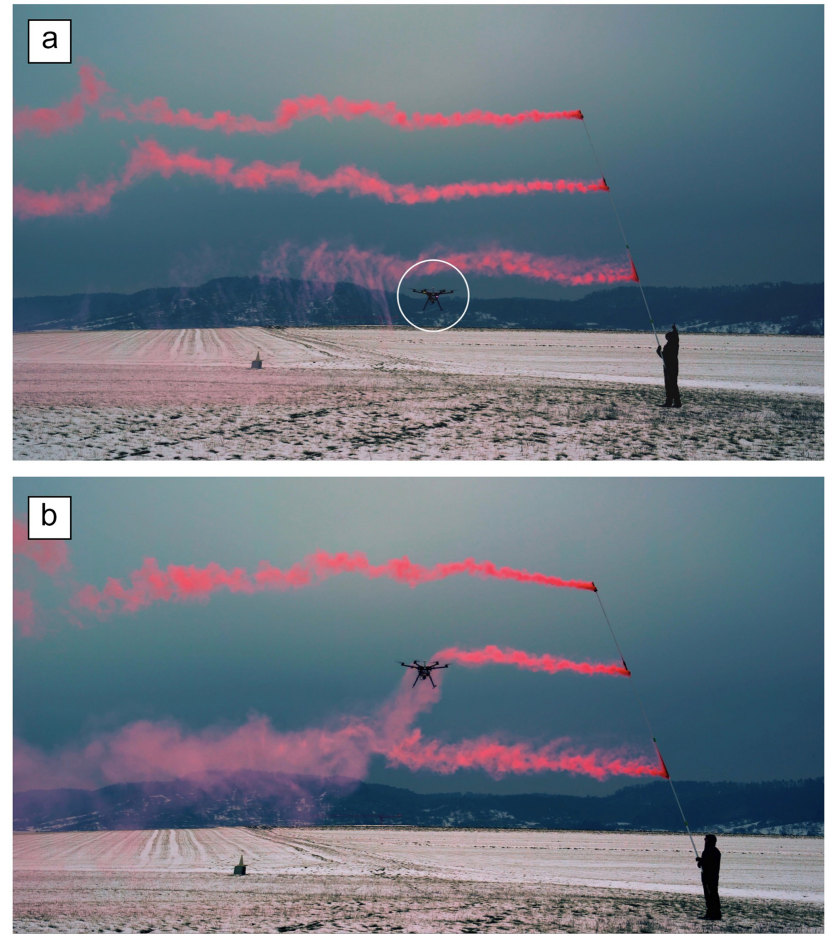

Figure 6. Investigation of the airflow pattern caused by the multicopter UAV (DJI S900) using three coloured pyrotechnical smoke cartridges with (a) flying the multicopter UAV below the lowest smoke plume, and (b) below the middle smoke plume; screenshots taken from a $30 \mathrm{~s}$ video sequence. Side wind from right to left. Dilution of the smoke plume and thus mixing of the surrounding air occurs essentially only on the lee side and below the multicopter UAV, while in windward and above the multicopter UAV, the approaching plume remains largely unaffected.

$\left(48.54322^{\circ} \mathrm{N}, 8.94865^{\circ} \mathrm{E}, 400 \mathrm{~m}\right.$ a.s.1.). For this purpose, three coloured pyrotechnical smoke cartridges (type AX 60, company BJÖRNAX AB, Nora, Sweden) were mounted and ignited at different positions on an erectable aluminium boom with the multicopter UAV flying at different elevations below and above the generated smoke plumes (Fig. 6). The whole experiment was filmed and the video sequences were analysed with regard to the resulting airflows.

Figure 6a shows that only the first (lowest) smoke plume approaching (due to prevailing side wind) about $80 \mathrm{~cm}$ above the multicopter UAV horizontally is influenced by the downwash caused by the propellers and accelerated vertically downwards. The second smoke plume $(2.4 \mathrm{~m}$ above the multicopter UAV) and the third smoke plume ( $4.0 \mathrm{~m}$ above the multicopter UAV) remain substantially unaffected. Furthermore, it is also shown that the first smoke plume is greatly diluted on the lee side (with respect of the side wind blowing from right to left) of the multicopter UAV, which is a result of the downward acceleration of the associated air mass. The upper-second and -third smoke plumes also experience some turbulence on the lee side but significantly less than the first 
smoke plume. As a result, the air mass on the lee side of the multicopter UAV seems to be much more affected by the downwash caused by the propellers than the air mass windward.

Figure $6 \mathrm{~b}$ shows a photograph with the multicopter UAV elevated only about $20 \mathrm{~cm}$ below the second smoke plume. It can be seen that the second smoke plume is directly captured by the propellers of the multicopter UAV. Thus, the second smoke plume is accelerated and accordingly diluted downwards. Also, the lower first smoke plume is heavily affected and disturbed by the downwash caused by the propellers of the multicopter UAV, whereas the upper-third smoke plume ( $1.8 \mathrm{~m}$ above the multicopter UAV) remains almost unaffected. For the present study, the dilution of the smoke plume was not of interest per se. Instead, the velocity (by magnitude and direction) of characteristic patterns of the smoke plume approaching the multicopter UAV was of interest, so it could be decided where the air intake of the PCS had to be arranged and how it had to be oriented to achieve substantial isokinetic sampling conditions. The results are discussed in Sect. 4.1.

\subsection{Particle extraction efficiency of the impactor (cascade test)}

In order to examine the effectiveness of the newly developed PCS with respect to its particle extraction rate, an experiment was carried out using two identical impactors connected in a cascade (Fig. 7). The experiment was carried out on the ground with the same operating conditions as during particle collection flights in order to ensure the comparability of the results. Prior to this experiment, all impactor housing and tubing components were carefully cleaned to ensure that all components used in these experiments are particle-free. Fresh sample carriers were inserted in both impactors. Then, the blower was operated for $10 \mathrm{~min}$ at a flow rate of $200 \mathrm{slm}$. The results are discussed in Sect. 4.2.

\subsection{Potential particle contamination of the sample carrier (contamination test)}

Upon analysing the sample carrier using an optical microscope, it cannot be distinguished whether the particles on the sample carrier were collected during the airborne particle collection operation or inadvertently by contamination before or after the sampling operation. By using a laminar airflow box as previously described, contamination during manufacture and storage can be reliably prevented. And with the experiments described in the following, it was examined whether and, if so, what number of particles were inadvertently applied to the sample carrier by the handling of the sample carrier on the ground at the site of operation as well as during the ascent and descent of the multicopter UAV.

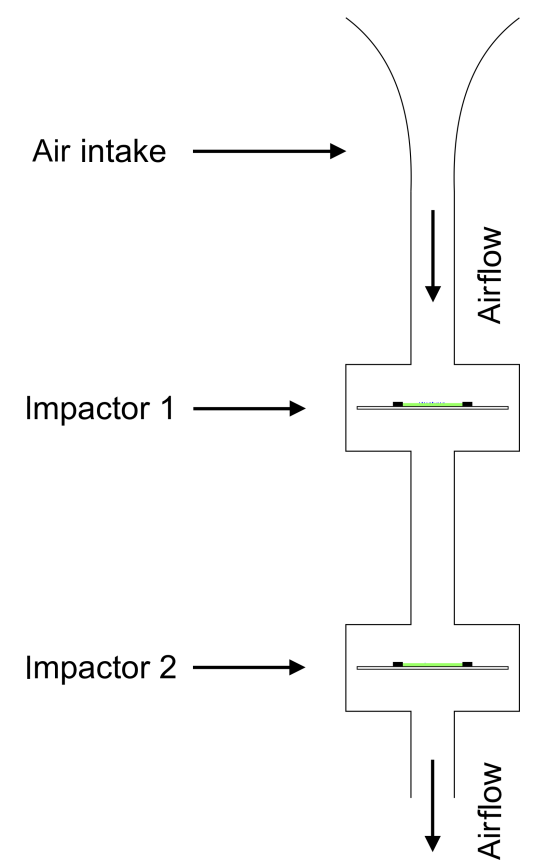

Figure 7. Schematic sketch of the extraction efficiency experiment with two identical impactors (impactor 1 and impactor 2) connected in a cascade configuration to investigate particle extraction efficiency. At $100 \%$ efficiency, all particles would be extracted by impactor 1 , leaving no particles for impactor 2 .

\subsubsection{Contamination on the ground}

At the site of operation, the particle sample carrier is exposed to atmospheric air during installation in and removal from the impactor. This exposure usually lasts less than $30 \mathrm{~s}$, but could lead to a contamination of the sample carrier with particles, in particular if the particle concentration in the ambient air is exceptionally high. In a first investigation carried out in the afternoon (14:15 to 14:30 local time) of 10 March 2017 at the airfield in Poltringen, a sample carrier was removed from its protective packaging and exposed to ambient air for $15 \mathrm{~min}$ on the roof of a car about $1.8 \mathrm{~m}$ a.g.l. The sample carrier was then repackaged and transported to the laboratory where it was treated and sealed in a particle-free laminar airflow box to prevent any further contamination. The results are discussed in Sect. 4.3.

\subsubsection{Contamination during ascent and descent}

As observed during the smoke plume tests, an inflow of air into the air inlet of the PCS appears during the hovering flight of the multicopter UAV, even if the blower of the particle collection system is switched off. It is expected that this inflow incorporates aerosol particles onto the sample carrier and thus has to be regarded as a potential source of contamination. During vertical ascent of the multicopter UAV with a typical speed of $6 \mathrm{~m} \mathrm{~s}^{-1}$ and the correspondingly higher 
propeller power, this effect is likely to be even more pronounced. Therefore, an experiment was carried out in the afternoon of 10 March 2017. A flight was carried out with the fully equipped multicopter UAV but with the blower of the PCS remained switched off. At the start, the multicopter UAV climbed up to an altitude of $300 \mathrm{~m}$ a.g.l with maximum ascent speed. After $1 \mathrm{~min}$ of hovering, the multicopter UAV descended to $50 \mathrm{~m}$ a.g.l., followed by a new ascent to an altitude of $200 \mathrm{~m}$ a.g.l with maximum climb rate. After $1 \mathrm{~min}$ of hovering the multicopter UAV descended to the ground and landed. Then, the sample was transported to the laboratory, where it was treated and sealed in the laminar airflow box as described earlier. In total, $450 \mathrm{~m}$ of ascent and descent in about $2.5 \mathrm{~min}$ was performed, plus $2 \mathrm{~min}$ hovering time. The results are discussed in Sect. 4.3.

\subsection{Aerosol particle collection flights}

Numerous aerosol particle collection flights were carried out in March 2017 to evaluate the scientific potential of a multicopter UAV equipped with the newly developed PCS. The major aim of developing such a PCS was the collection of aerosol particles at different altitudes and their quantitative determination. For the present study we focused at first on the quantitative determination of the concentration of pollen grains. The airfield in Poltringen near Tübingen in Germany was chosen as the launch site with regard to an existing official flight permit for UAV flights up to an altitude of $300 \mathrm{~m}$ a.g.l. The airfield is located on an elevated plain above the Ammer Valley that is intensely used for agriculture. The site is about $2 \mathrm{~km}$ away from the $150 \mathrm{~km}^{2}$ large Schönbuch Forest, a natural reserve, mainly consisting of mixed deciduous and coniferous forest extending to the NE and forming an escarpment in the landscape arising about $70 \mathrm{~m}$ from the basal plain.

Three series of aerosol particles collection flights were carried out on 3, 10, and 16 March 2017, at the airfield in Poltringen with three flights each day. Table 1 gives an overview of these aerosol particle collection flights, including data concerning the hovering altitude above ground level, at which the blower of the particle collection system was activated, the airborne particle collection start time, as well as the measured air temperature, wind direction, and wind speed on the ground. On 3 March 2017, the blower of the PCS was activated during hovering in 25,100 , and $200 \mathrm{~m}$ a.g.l. and also - as an additional measurement - on the ground with the propellers of the multicopter UAV not being in operation. On 10 and 16 March 2017, the PCS was activated during flights in 25, 200, and $300 \mathrm{~m}$ a.g.l. The particle collection duration at each altitude was $10 \mathrm{~min}$, with a sampled air volume of 2000 standard litres, corresponding to $2 \mathrm{~m}^{3}$ under standard conditions, which are $20^{\circ} \mathrm{C}$ and $1013.25 \mathrm{hPa}$ according to the data sheet of the mass flow sensor.

Prior to each day of aerosol particle collection flights, the bell-mouth-shaped air inlet, the tube leading to the impactor, the $\mathrm{O}$ ring and the two housing halves were cleaned in an ultrasonic bath with soapy water for $15 \mathrm{~min}$, then rinsed with deionized, filtered water $(0.3 \mu \mathrm{m}$ membrane filter $)$ and dried in a particle-free environment (laminar airflow box, HEPA H14 filter). Once the parts were dried, the impactor was assembled (excluding sample carrier) and packed together with the inlet into a new, clean, sealable storage bag.

In the field again, shortly before the particle collection operation, the impactor was taken out of the sealed storage bag, the sample carrier was installed in the impactor and the inlet was plugged onto the tube leading to the impactor. In between the sampling flights, shortly before the next flight operation and shortly before installation of the next unloaded sample carrier, the impactor and the bell-mouth-shaped inlet were flushed with filtered air using an battery-operated electric blower with a medical ventilation filter installed on its inlet (type Pall Ultipor 100, > 99.999 \% retention of airborne bacteria and viruses).

The sample carriers were treated post-flight as described previously. Identification and counting of the collected particles were visually performed using a Olympus transmitted light microscope BX50 at 400 times magnification. The entire area of the slides was counted row by row. Identification was assisted by a reference collection and literature (Beug, 2004). The results are discussed in Sect. 4.4.

\section{Results and discussion}

\subsection{Position of the air inlet with regard to isokinetic sampling (smoke plume test results)}

The smoke plume tests allow a quantitative determination of the airflow velocities. Despite their limited resolution, the results obtained here are in good agreement with the CFD calculations reported by Haas et al. (2014): the smoke plume approaching $20 \mathrm{~cm}$ above the propellers of the multicopter UAV is directly captured by the propellers (Fig. 6b, middle smoke plume). Also, the smoke plume approaching $80 \mathrm{~cm}$ above the multicopter UAV is strongly affected and accelerated downwards (Fig. 6a, lower smoke plume). The smoke plume approaching $1.8 \mathrm{~m}$ above the multicopter UAV, on the other hand, is already only very slightly affected (Fig. 6b, upper smoke plume). The smoke plume approaching $2.4 \mathrm{~m}$ above the multicopter UAV remains unaffected (Fig. 6a, middle smoke plume). Thus, these results correspond very well to the CFD calculations reported by Haas et al. (2014), according to which the air volume mixed by the propellers of the multicopter UAV extends only about $2 \mathrm{~m}$ above the multicopter UAV. In addition, Fig. $6 \mathrm{~b}$ also shows that the air volume mixed by the propellers extends further below the multicopter UAV than above the multicopter UAV, as predicted by the CFD calculations.

With regard to the isokinetic sampling conditions concerning the direction of the airflow velocity vectors, it was ob- 
Table 1. Aerosol particle collection flights carried out on 3, 10, and 16 March 2017 performed at different hovering altitudes.

\begin{tabular}{|c|c|c|c|c|c|}
\hline Date & $\begin{array}{l}\text { Altitude } \\
\text { a.g.l. }\end{array}$ & $\begin{array}{r}\text { Start time of } \\
\text { particle } \\
\text { collection }\end{array}$ & $\begin{array}{l}\text { Air } \\
\text { temperature } \\
\text { on the ground }\end{array}$ & $\begin{array}{l}\text { Wind } \\
\text { direction } \\
\text { on the ground }\end{array}$ & $\begin{array}{l}\text { Wind } \\
\text { speed on } \\
\text { the ground }\end{array}$ \\
\hline March 3, 2017 & multicopter on the ground & $15: 55$ & & & \\
\hline March 3, 2017 & $25 \mathrm{~m}$ & $15: 20$ & & & \\
\hline March 3, 2017 & $100 \mathrm{~m}$ & $15: 05$ & $15^{\circ} \mathrm{C}$ & NO & $1 \mathrm{~ms}^{-1}$ \\
\hline March 3, 2017 & $200 \mathrm{~m}$ & $15: 44$ & & & \\
\hline March 10, 2017 & $25 \mathrm{~m}$ & $14: 57$ & & & \\
\hline March 10, 2017 & $200 \mathrm{~m}$ & $14: 38$ & $17^{\circ} \mathrm{C}$ & $\mathrm{O}$ & $1.8 \mathrm{~m} \mathrm{~s}^{-1}$ \\
\hline March 10, 2017 & $300 \mathrm{~m}$ & $15: 40$ & & & \\
\hline March 16, 2017 & $25 \mathrm{~m}$ & $14: 18$ & $19^{\circ} \mathrm{C}$ & $\mathrm{S}$ & $1.9 \mathrm{~m} \mathrm{~s}^{-1}$ \\
\hline March 16, 2017 & $200 \mathrm{~m}$ & $13: 55$ & $19^{\circ} \mathrm{C}$ & $\mathrm{S}$ & $1.8 \mathrm{~m} \mathrm{~s}^{-1}$ \\
\hline March 16, 2017 & $300 \mathrm{~m}$ & $14: 40$ & $20^{\circ} \mathrm{C}$ & $\mathrm{W}$ & \\
\hline
\end{tabular}

served that a plume of smoke approaching horizontally (due to prevailing side wind) $50 \mathrm{~cm}$ above the propellers of the multicopter UAV is caught by the downwash produced by the propellers and accelerated vertically downwards. When the smoke plume reaches the propellers, it is completely deflected from the original horizontal flow direction into a vertical flow direction. Already $30 \mathrm{~cm}$ above the propellers, the smoke plume is deflected in the vertical direction to the extent that it encloses an angle of about $20^{\circ}$ with the vertical direction. As a result of these observations it was decided to orient the air inlet of the PCS vertically upward and to position its open end $30 \mathrm{~cm}$ above the propellers of the multicopter UAV. In this position, the bell-mouth shape of the air inlet of the PCS enables substantial isokinetic sampling with regard to the direction of the airflow velocity vectors, at least during hovering mode of the multicopter UAV and with side winds of less than $3 \mathrm{~m} \mathrm{~s}^{-1}$, independently of the direction of the side wind.

With regard to the isokinetic sampling conditions concerning the magnitude of the velocity vectors, successive frames of the video sequences recorded during the visual airflow tests were evaluated. A horizontally approaching smoke plume begins to deflect in a vertical direction. Within three frames of the recorded video sequences, corresponding to $0.12 \mathrm{~s}$, characteristic sections of the smoke plume cover a vertical distance between 15 and $20 \mathrm{~cm}$, thus vertically arriving at a level about $30 \mathrm{~cm}$ above the propellers of the multicopter UAV where the air inlet of the PCS is positioned. Under the simplified assumption of a uniform vertical acceleration, the vertical velocity component at this level can be calculated to be between 2.5 and $3.3 \mathrm{~m} \mathrm{~s}^{-1}$. As the assumption of a uniform vertical acceleration is probably a strong simplification of the actual circumstances, a more precise determination of the vertical acceleration and velocity of the airflow above the multicopter UAV would be a valuable aspect of future work on this subject.
The circular opening of the free (wider) end of the bellmouth-shaped air inlet has an inner diameter of $69 \mathrm{~mm}$ (Fig. 2). Thus, at an airflow volume of $200 \mathrm{~L} \mathrm{~min}^{-1}$, the average flow velocity is about $0.9 \mathrm{~m} \mathrm{~s}^{-1}$. Since it has to be assumed that the airflow velocity at the edge of the bell-mouthshaped air inlet is significantly lower than in its centre, the flow velocity at the centre is to be expected above the average value of $0.9 \mathrm{~m} \mathrm{~s}^{-1}$. This value is probably still less than the previously estimated vertical velocity component of the air to be drawn in. Thus, despite the high airflow volume of $200 \mathrm{~L} \mathrm{~min}^{-1}$ drawn in, a somewhat sub-isokinetic sampling is to be assumed with regard to the magnitude of velocity vectors. If necessary, the opening of the free end of the bellmouth-shaped air inlet can be varied for future sampling operations to even better match the isokinetic sampling conditions.

As a result, positioning the air inlet of the PCS $30 \mathrm{~cm}$ above the propellers of the multicopter UAV in combination with the vertically oriented and appropriately dimensioned bell-mouth-shaped air inlet ensures substantial isokinetic sampling conditions at high airflow volumes of $200 \mathrm{~L} \mathrm{~min}^{-1}$, even - within certain limits - regardless of prevailing side wind direction and speed.

\subsection{Extraction efficiency of the impactor (cascade test results)}

The extraction efficiency of the impactor was determined by visual analysis of sample carriers of two identical impactors connected in a cascade and filled with the same airflow as shown schematically in Fig. 7. At an ideal extraction efficiency of $100 \%$, all particles would be extracted by impactor 1 and thus no particles would be deposited on the sample carrier of impactor 2. The results of the visual analysis are shown in Table 2.

The particle extraction and retention capability of the newly developed PCS was demonstrated for pollen of the 
Table 2. Number of pollen grains collected in impactor 1 and impactor 2 of the arrangement of Fig. 7 for determination of the retention rate and thus the extraction efficiency of the newly developed impactor.

\begin{tabular}{lrrr}
\hline Number of counted pollen grains on impactor stage $N_{1}$ and $N_{2}$ \\
\hline Genus & $\begin{array}{l}\text { Upstream } \\
\text { impactor } N_{1}\end{array}$ & $\begin{array}{c}\text { Downstream } \\
\text { impactor } N_{2}\end{array}$ & $R=\begin{array}{r}\text { Retention rate } \\
N_{1} /\left(N_{1}+N_{2}\right)\end{array}$ \\
\hline Taxus & 806 & 3 & $99.63 \%$ \\
Alnus & 194 & 2 & $98.97 \%$ \\
Corylus & 49 & 1 & $97.96 \%$ \\
Pinus & 1 & 0 & $100.00 \%$ \\
\hline Total & 1050 & 6 & $99.43 \%$ \\
\hline
\end{tabular}

genera Taus, Alnus, and - with restrictions concerning the statistical database - Corylus and Pinus, which were present in the air at the time of the extraction efficiency experiment. While the number of pollen grains of the genera Corylus and Pinus are regarded to be too small for a statistical evaluation, the number of pollen grains of the genera Taxus and Alnus collected in upstream impactor no. 1 were about 100 to 250 times the number of corresponding particles collected in downstream impactor no. 2 . As a result, the extraction efficiency, or retention ratio, of the impactor is at least $98 \%$ under the given conditions $\left(200 \mathrm{~L} \mathrm{~min}^{-1}\right)$, concerning the pollen grains of genera Taxus, Alnus, and Corylus.

With regard to the question of whether this high extraction and retention rate also applies to other particles, i.e. to smaller particles, it should be noted that in the widely used Burkard pollen trap a mean jet velocity of $6 \mathrm{~m} \mathrm{~s}^{-1}$ is sufficient to reliably extract pollen grains and spores from the air. Furthermore, a modified orifice with a reduced width of $0.5 \mathrm{~mm}$ is available, which increases the mean jet velocity to $24 \mathrm{~m} \mathrm{~s}^{-1}$ in order to improve the trapping efficiency for particles in the diameter range 1-10 $\mu \mathrm{m}$ (Datasheet Burkard 7 Day Recording Volumetric Spore Sampler, Burkard Scientific). As shown in Fig. 9, the newly developed impactor (working with a mean jet velocity of $50 \mathrm{~m} \mathrm{~s}^{-1}$ ) extracts aerosol particles having a size between the resolution limit of the light microscope (in the range of $1 \mu \mathrm{m}$ ) and approximately $60 \mu \mathrm{m}$. Further investigations are necessary to check whether the high extraction rates (of at least $98 \%$ ) determined for pollen of the genera Taxus, Alnus, and Corylus (with a typical size between 20 and $30 \mu \mathrm{m}$ ) also apply to particles in the $\mu \mathrm{m}$ and sub- $\mu \mathrm{m}$ range.

\subsection{Measurement errors and particle contamination (contamination test results)}

The PCS, the visual identification, and the counting of particles are subject to various influences, which potentially form a source of errors with regard to the determination of the actual concentration of particles in the ambient air. An

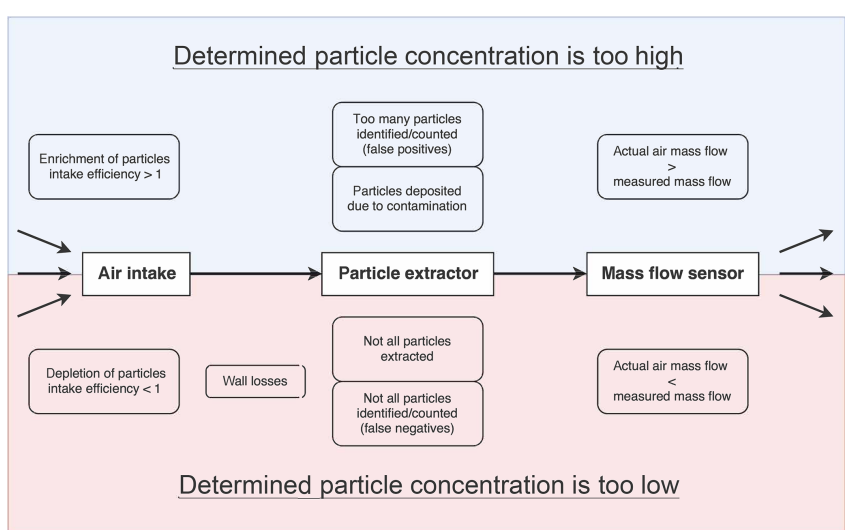

Figure 8. Overview of the possible influences of the different components of the newly developed particle collection system (PCS) on the final determined particle concentration. The components of the PCS, in which the influences can occur, namely air inlet, impactor, and mass flow sensor, are arranged along the horizontal axis. Influences that can lead to the determination of a particle concentration higher than the actual particle concentration are shown in the upper half of the figure (blue background), whereas the influences that can lead to the determination of a particle concentration lower than the actual particle concentration are shown in the lower half of the figure (red background).

overview of these influences in the different components of the PCS, namely air inlet, impactor, and mass flow sensor, is given in Fig. 8.

The first source of measurement error might occur during the air intake. If the ambient air is not drawn in under isokinetic conditions, i.e. with the same velocity (by magnitude and direction) as the air approaching the air inlet, then the drawn-in air might be enriched or depleted with particles due to mass inertia effects. The multicopter UAV airflow tests have shown that the suitable placement and design of the bell-mouth-shaped air inlet, in combination with the operation of the PCS on board the multicopter UAV in hovering flight mode, result in almost isokinetic sampling conditions provided there are no excessive side winds. In order to be able to give an estimate of the error caused by non- $100 \%$ ideal isokinetic sampling, further investigations are required. A loss of particles, which have already been drawn in, could occur due to adhesion to the wall of the air inlet as well as to the wall of the downstream connecting pipes ("wall losses", Fig. 8). It is expected that such wall losses are of minor importance for the newly developed PCS with regard to its high airstream velocity of about $50 \mathrm{~m} \mathrm{~s}^{-1}$ in the connecting pipe upstream of the impactor. In the impactor itself, an incomplete extraction of the particles would lead to an insufficient number of particles deposited on the sample carrier. However, according to the experiments performed within the scope of this study, the particle extraction rate of the impactor is at least $98 \%$ for pollen grains. 
Particle contamination is a potential error source that leads to higher particle numbers deposited on the sample carrier. Within the present study, experiments were performed concerning potential contamination on the ground as well as particle contamination during ascent and descent of the multicopter UAV. Concerning the potential particle contamination on the ground, a total of four pollen grains were identified on the sample carrier, i.e. 2 of the genus Taxus, 1 of the genus Alnus, and 1 of the genus Corylus, as the result of a $15 \mathrm{~min}$ exposure of the uncovered sampling carrier to the ambient air. This small number is certainly also due to the lack of local sources such as pollinating trees or bushes within a radius of $150 \mathrm{~m}$ around the location of exposure (airfield in Poltringen).

For the evaluation of these results, the concentration of the pollen grains in the ambient air must be taken into account. The contamination experiments were carried out on 10 March 2017 at the same time as the aerosol particle collection flights. The mean values of the concentrations measured at the three altitudes $(25 \mathrm{~m}, 200 \mathrm{~m}$, and $300 \mathrm{~m}$ a.g.1.) are 53 pollen grains per $\mathrm{m}^{3}$ of the genus Taxus, 44 pollen grains per $\mathrm{m}^{3}$ of the genus Alnus, and 16 pollen grains per $\mathrm{m}^{3}$ of the genus Corylus (Table 9). Thus, the contamination during the exposure of the sample carrier for $15 \mathrm{~min}$ on the ground represents between $3 \%$ and $6 \%$ of the number of pollen particles in $1 \mathrm{~m}^{3}$ of ambient air. With regard to the fact that the sample carrier is exposed to ambient air for handling purposes usually for less than $30 \mathrm{~s}$, a contamination of $0.1 \%-0.2 \%$ is expected, which is negligible for most applications. This small particle contamination on the ground can be further reduced or even excluded by employing a mobile laminar airflow box in the field. Furthermore, the lateral position of the particles deposited on the gelatine surface of the sample carrier enables us to know whether the particles were deposited during sampling or are the result of contamination on the ground: while particles deposited during the sampling operation are within a circle corresponding to the contour of the open jet, particles deposited by contamination on the ground are statistically distributed over the entire surface.

More relevant is the contamination of the particle sample carrier during ascent and descent of the multicopter UAV. During the corresponding contamination experiment, $450 \mathrm{~m}$ of ascent and descent were performed within $2.5 \mathrm{~min}$, and in addition $2 \mathrm{~min}$ of hovering in $200 \mathrm{~m}$ and $300 \mathrm{~m}$ a.g.l. In total 17 pollen grains, 8 of the genus Taxus, 6 of the genus Alnus, and 3 of the genus Corylus, were identified on the sample carrier. As a result, the number of pollen grains deposited on the sample carrier during ascent, hovering, and descent represents between $15 \%$ and $19 \%$ of the number of pollen in $1 \mathrm{~m}^{3}$ of ambient air. If, for simplification, the contamination during hovering is neglected, then a contamination of $3 \%-$ $4 \%$ for every $100 \mathrm{~m}$ ascent and descent is caused. As a result, relevant contamination of the particle sample carrier may occur during ascent and descent of the multicopter UAV. The extent of the contamination depends on the altitude the mul- ticopter UAV is elevated to, and also depends on the particle concentration in the layers of air crossed by the multicopter UAV during ascent and descent.

During the visual identification and counting of the particles, it is possible that contrast differences when using the transmitted light microscope are erroneously identified as particles (false positives) and/or that some particles are counted twice. Furthermore, it is possible that some particles are not or not correctly identified (false negative) and/or that some particles are overlooked. This potential source of error was excluded in the present study by entrusting particularly experienced scientists with the visual identification and counting of the particles, which still is the golden standard for pollen concentration measurement (Oteros et al., 2015).

Finally, a potential error source exists with regard to the accuracy of the mass flow sensor SFM3000-200-C. It is evident that any difference between the actual and measured air mass flow produces a corresponding error in the determined particle concentration. According to the data sheet of the mass flow sensor, within the temperature range of -20 to $+80^{\circ} \mathrm{C}$, the error is typically $1.5 \%$, but $2.5 \%$ at maximum, of the measured value.

\subsection{Airborne particle collection operation}

\subsubsection{Results of the aerosol particle collection flights}

The number of particles collected during the aerosol particle collection flights on 3, 10, and 16 March 2017 from $2 \mathrm{~m}^{3}$ of sampled air and subsequently counted by visual microscopic analysis of the respective sample carriers are summarized in Table 3.

Only pollen of the genera Taxus, Corylus, Alnus, Cyperaceae, and Salix were counted and listed, as well as two types of fungal spore. Fungal spore type 1 probably belongs to the genus Cladosporium, whereas fungal spore type 2 most likely belongs to the genus Epicoccum. Furthermore, large opaque particles with a longitudinal extension of more than $20 \mu \mathrm{m}$ were counted: many of these particles have a wood-fibre-like structure and the appearance of residues of burned wood or charcoal. Additionally, a large number of small aerosol particles down to a size of less than $1 \mu \mathrm{m}$ were visible under the microscope, but are not listed as they cannot be reliably identified by visual inspection only. Figure 9 shows a photograph of the sample carrier content as an example of one of the collection flights.

The amount of collected pollen grains, fungal spores, and large $(>20 \mu \mathrm{m})$ opaque particles vary significantly among the 3 sampling days as well as within each sampling day with the respective sampling altitude above ground level. Generally, the results reflect the expected type and concentration of pollen usual for this season (Fig. 10).

Only the numbers of the pollen of the genera Taxus, Cory-

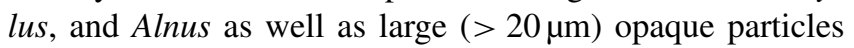
were high enough (i.e. more than 10 particles per $\mathrm{m}^{3}$ ) to 
Table 3. Summary of the number of collected particles (from $2 \mathrm{~m}^{3}$ sampled air) using the new particle collection system (PCS) on board the multicopter UAV during the aerosol particle collection flights carried out in March 2017 (top). In addition, the comparison of these measured values with the forecast data of the Deutscher Polleninformationsdienst (PID) (middle) and the pollen concentrations measured by MeteoSwiss with a commercially available Burkard pollen sampler in Zürich (bottom).

\begin{tabular}{|c|c|c|c|c|c|c|c|c|c|c|}
\hline \multirow{3}{*}{$\begin{array}{l}\text { Collection start time (local time) } \\
\text { Flight altitude (in m a.g.l) }\end{array}$} & \multicolumn{4}{|c|}{3 March } & \multicolumn{3}{|c|}{10 March } & \multicolumn{3}{|c|}{16 March } \\
\hline & $15: 55$ & $15: 20$ & $15: 05$ & $15: 44$ & $14: 57$ & $14: 38$ & $15: 40$ & $14: 18$ & $13: 55$ & $14: 40$ \\
\hline & ground & $25 \mathrm{~m}$ & $100 \mathrm{~m}$ & $200 \mathrm{~m}$ & $25 \mathrm{~m}$ & $200 \mathrm{~m}$ & $300 \mathrm{~m}$ & $25 \mathrm{~m}$ & $200 \mathrm{~m}$ & $300 \mathrm{~m}$ \\
\hline Taxus & 32 & 22 & 24 & 2 & 113 & 133 & 70 & 135 & 175 & 88 \\
\hline Corylus & 27 & 35 & 30 & 29 & 32 & 36 & 26 & 4 & 1 & - \\
\hline Alnus & 128 & 167 & 159 & 181 & 109 & 91 & 63 & 18 & 11 & 12 \\
\hline Cyperaceae & - & - & - & - & 5 & 2 & 2 & - & - & - \\
\hline Salix & - & 3 & 2 & 1 & 9 & 3 & 5 & 23 & 3 & 10 \\
\hline Fungal spores type 1 & 22 & 5 & 17 & 2 & 200 & 114 & 131 & 2 & 2 & 2 \\
\hline Fungal spores type 2 & 16 & 1 & 3 & 4 & 3 & 4 & 4 & 2 & 5 & 3 \\
\hline Opaque particles $>20 \mu \mathrm{m}$ & 2 & 11 & 4 & 9 & 52 & 33 & 26 & 30 & 34 & 16 \\
\hline
\end{tabular}

Comparison to the Statement of the Deutscher

Polleninformationsdienst (PID)

\begin{tabular}{|c|c|c|c|}
\hline & \multicolumn{3}{|c|}{$\begin{array}{l}\text { Statement of the Deutscher Polleninformationsdienst } \\
\text { (PID) ("Wochenpollenvorhersage") }\end{array}$} \\
\hline & Week of 1 March 2017 (KW9) & Week of 8 March 2017 (KW10) & Week of 15 March (KW 11) \\
\hline Pollen of the genera Taxus & $\begin{array}{l}\text { first weak load ("erste } \\
\text { schwache Belastung") }\end{array}$ & $\begin{array}{l}\text { short time, large amount } \\
\text { ("kurze Zeit große Menge") }\end{array}$ & $\begin{array}{l}\text { the most abundant genus of } \\
\text { Pollen ("die mengenmaäßig } \\
\text { häufigste Pollenart") }\end{array}$ \\
\hline $\begin{array}{l}\text { Pollen of the genera } \\
\text { Corylus and Alnus }\end{array}$ & $\begin{array}{l}\text { first high concentration } \\
\text { ("erstmals hohe Konzentration") }\end{array}$ & $\begin{array}{l}\text { approaches the end } \\
\text { ("nähert sich dem Ende") }\end{array}$ & $\begin{array}{c}\text { faded } \\
\text { ("abgeblüht") }\end{array}$ \\
\hline \multicolumn{4}{|c|}{$\begin{array}{l}\text { Comparison to the measurements of MeteoSwiss } \\
\text { performed in Zürich }\end{array}$} \\
\hline \multirow[b]{2}{*}{ Corylus } & 3 March 2017 & 10 March 2017 & 16 March 2017 \\
\hline & \multicolumn{3}{|c|}{$\begin{array}{l}\text { Number of pollen } \\
\text { grains per } \mathrm{m}^{3}\end{array}$} \\
\hline PCS in Poltringen (25 m a.g.1.) & 18 & 16 & 2 \\
\hline Burkard sampler in Zürich & 41 & 20 & 5 \\
\hline Alnus & \multicolumn{3}{|c|}{$\begin{array}{l}\text { Number of pollen } \\
\text { grains per } \mathrm{m}^{3}\end{array}$} \\
\hline PCS in Poltringen (25 m a.g.l.) & 84 & 55 & 9 \\
\hline Burkard sampler in Zürich & 39 & 45 & 8 \\
\hline
\end{tabular}

allow a reliable statistical evaluation. Pollen of the genus Salix appeared only in small numbers during all 3 sampling days, and pollen of the genus Cyperaceae were even collected solely on 10 March 2017. Fungal spores of types 1 and 2 occurred on all 3 sampling days only in small numbers, except on 10 March 2017, when the fungal spores of type 1 were collected in a remarkably large number.

For all sampling altitudes, the concentration of pollen of the genus Taxus increased in the period between 3 and 16 March. For example, the concentration value measured at an altitude of $25 \mathrm{~m}$ a.g.1. rose from 11 pollen grains per $\mathrm{m}^{3}$ on 3 March to 57 pollen grains per $\mathrm{m}^{3}$ on 10 March and finally to 68 pollen grains per $\mathrm{m}^{3}$ on 16 March. Contrary to that, the concentration of pollen of the genus Alnus at an altitude of $25 \mathrm{~m}$ a.g.l. decreased from 84 pollen grains per $\mathrm{m}^{3}$ on 3 March to 55 pollen grains per $\mathrm{m}^{3}$ on 10 March and finally to 9 pollen grains per $\mathrm{m}^{3}$ on 16 March. The concentration of pollen of the genus Corylus measured on 3 and 10 March remained almost constant, but decreased significantly on 16 March. For example, at an altitude of $25 \mathrm{~m}$ a.g.l., 18 pollen grains per $\mathrm{m}^{3}$ were counted on 3 March, 16 pollen grains per $\mathrm{m}^{3}$ on 10 March, but only 2 pollen grains per $\mathrm{m}^{3}$ 

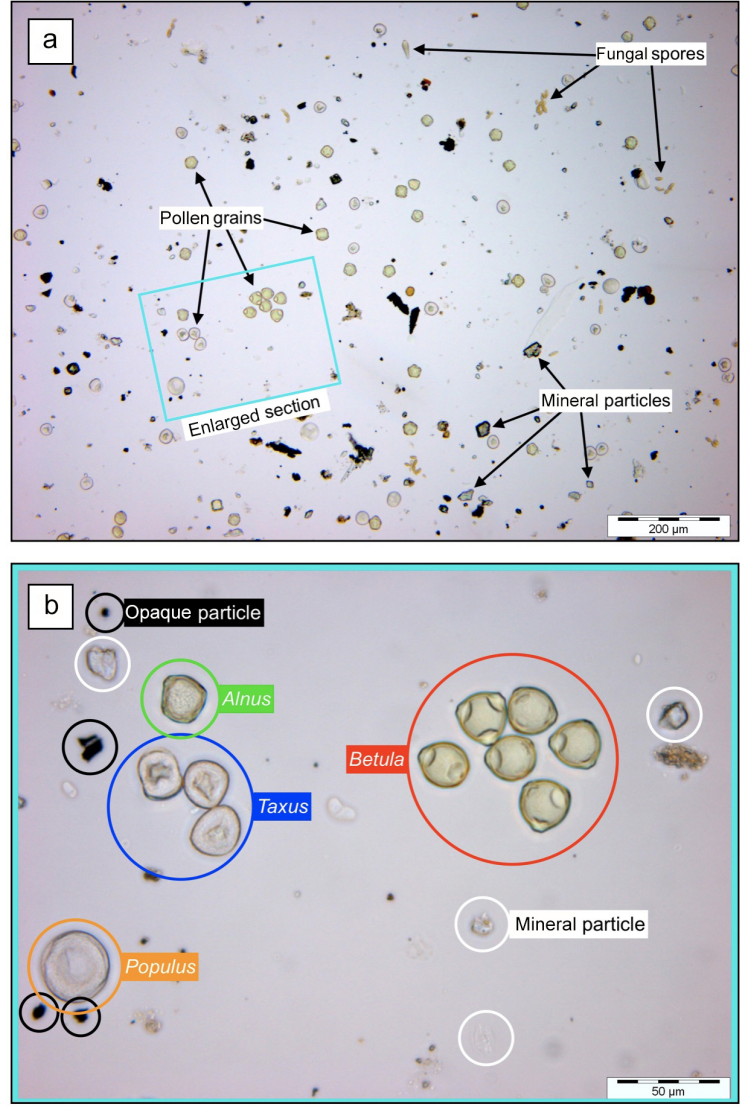

Figure 9. (a) Microscope photograph of a sample carrier loaded with various aerosol particles deposited during a multicopter UAV collection flight at an altitude of $300 \mathrm{~m}$ a.g.l. The section bounded by the cyan rectangle is shown enlarged in (b). (b) Enlargement shows clusters of Corylus and Taxus pollen grains as well as transparent mineral and opaque particles in various sizes.

on 16 March. Spores of types 1 and 2 were collected in consistently small numbers of less than 10 spores per $\mathrm{m}^{3}$ in the period between 3 and 16 March. One exception appeared on 10 March when the concentration values of spores of type 1 reached more than 50 spores per $\mathrm{m}^{3}$ at all three sampling altitudes (Fig. 10).

For many of the pollen genera collected during the particle collection flights in March 2017, the pollen grain concentrations measured at altitudes of $100 \mathrm{~m}, 200 \mathrm{~m}$, and $300 \mathrm{~m}$ a.g.l. are of the same order of magnitude as the pollen grain concentration measured near the ground $(25 \mathrm{~m})$ This applies in particular to the pollen genera detected in a large number during the measuring flights. One possible explanation for this observation is that all particle collection flights were carried out in the afternoon between 14:00 and 16:00 local time during early spring days with relatively high number of sunshine hours and no rain. It can be therefore assumed that on each of the 3 days a convective boundary layer had formed, comprising of mixed air, thus homogenizing the concentra-

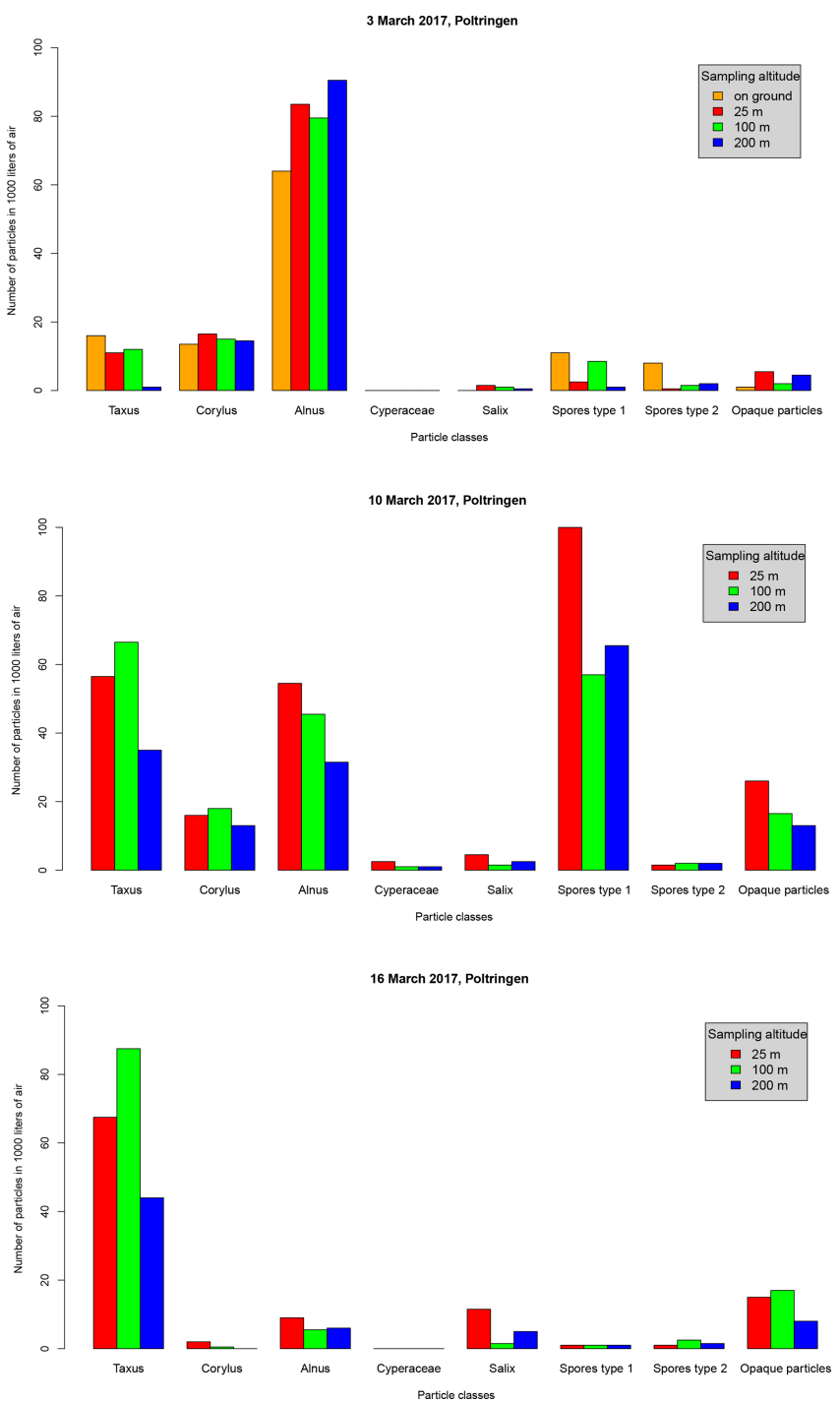

Figure 10. Graphical representation of the measured concentrations of particles (in particles per $\mathrm{m}^{3}$ of sampled air) collected during the aerosol particle collection flights on 3, 10, and 16 March 2017. Colour differences in the individual bars represent the particle concentration at different altitudes. It should be noted that only on 3 March 2017, a sampling operation was carried out on the ground with the propellers of the multicopter UAV switched off. On that date, sampling operations were carried out also at altitudes of $25 \mathrm{~m}$, $100 \mathrm{~m}$, and $200 \mathrm{~m}$ a.g.1., whereas on 10 and 16 March 2017 sampling operations were carried out at altitudes of $25 \mathrm{~m}, 200 \mathrm{~m}$, and $300 \mathrm{~m}$ a.g.l., respectively.

tion of the aerosol particles. This mixing process takes place within the entire convective boundary layer, usually extending up to altitudes of 1000 to $2000 \mathrm{~m}$ a.g.l. in the afternoon (Stull, 2012). It also can be concluded that the sources of the collected pollen were not only local, but regional; otherwise a higher concentration would have been observed near the ground close to the local pollen source. 

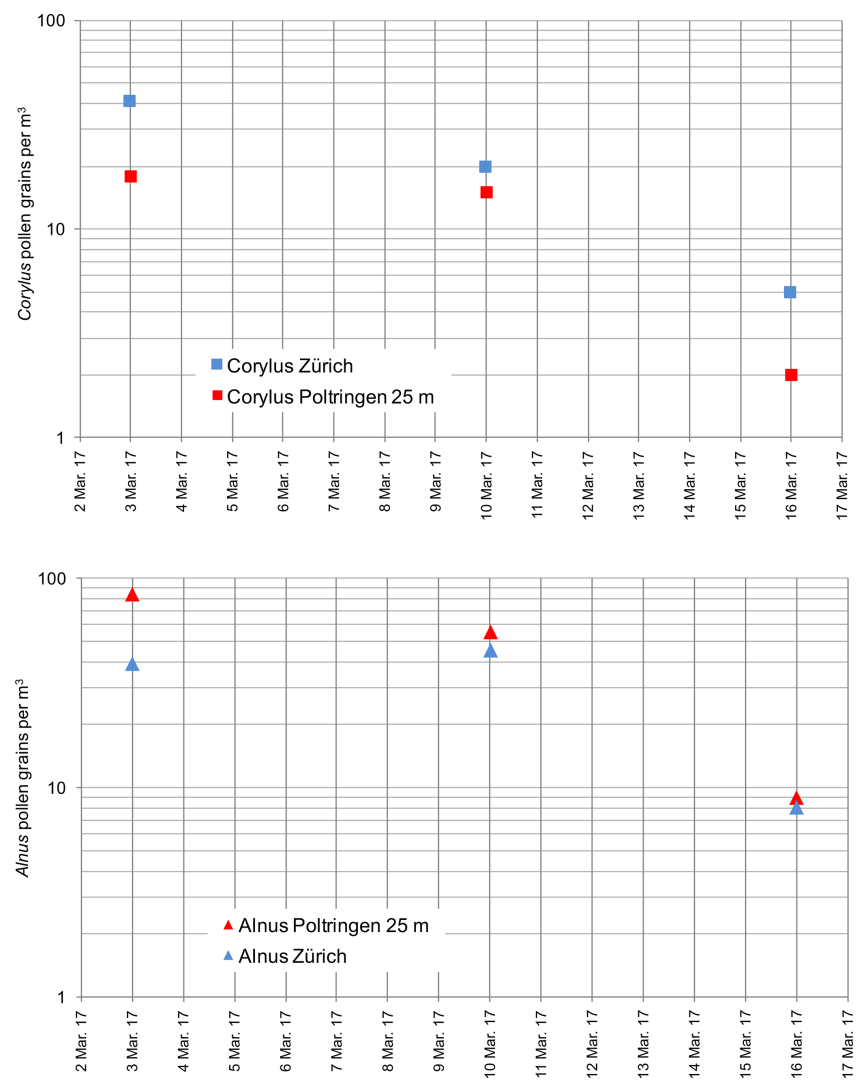

Figure 11. Concentrations of pollen of the genera Corylus and Alnus collected in Poltringen with the new particle collection system (PCS) operated on board the multicopter UAV during hovering at $25 \mathrm{~m}$ a.g.l. on 3, 10, and 16 March 2017 in comparison with pollen concentrations of the same genera published by MeteoSwiss in Zürich measured by using a Burkard pollen sampler. The lowest altitude above ground level data for Poltringen are available from $25 \mathrm{~m}$ a.g.l. for all 3 sampling days.

During the measuring flights on 10 and 16 March 2017, the concentration of pollen of the genus Taxus, which was the most frequently occurring pollen type at this time, was even higher at an altitude of $200 \mathrm{~m}$ a.g.l. than at $25 \mathrm{~m}$ a.g.l. When interpreting these results, it has to be kept in mind that the measuring flights at the different altitudes were carried out shortly after one another and within a period of about $30 \mathrm{~min}$, but not concurrently. Thus, it cannot be completely ruled out that the higher pollen concentration at an altitude of $200 \mathrm{~m}$ a.g.l. is merely the result of a short-time change in the overall pollen concentration at the measuring site, for example due to gusting wind. On the other hand, it is remarkable that this phenomenon was observed both on 10 March, when the concentration at $200 \mathrm{~m}$ a.g.l. was $18 \%$ higher than at $25 \mathrm{~m}$ a.g.l., and on $16 \mathrm{March}$, when the concentration at $200 \mathrm{~m}$ a.g.l. was even $30 \%$ higher than at $25 \mathrm{~m}$ a.g.l.

The observation that the pollen grain concentration was higher at elevation than on the ground is in good agreement with the results of Comtois et al. (2000), who con- ducted pollen concentration measurements using a tethered balloon up to an altitude of $600 \mathrm{~m}$ a.g.l. Their results revealed that the pollen grain concentration at $600 \mathrm{~m}$ a.g.l. can be similar to or, depending on the pollen genus, even higher than on the ground. Also, Damialis et al. (2017) recently reported a higher pollen concentration even at an altitude of $2000 \mathrm{~m}$ a.g.l. compared to the values measured on the ground.

During the measuring flights on 10 March 2017 for both the pollen of the genera Taxus and Corylus, the highest pollen concentration values were measured at an altitude of 200 m a.g.l., whereas for pollen of the genus Alnus the highest pollen concentration values were measured at an altitude of $25 \mathrm{~m}$ a.g.l. This might be an indication that the transport mechanisms and corresponding transport parameters are significantly specific to the respective pollen genus, even possibly resulting in the transport of pollen at genus-specific circumstances and altitudes. In order to gain in-depth knowledge of this topic, further experiments are necessary, such as concurrent measurements of pollen concentrations at different altitudes.

During the measuring flights on 3 March 2017, in addition to the aerial sampling at various altitudes, one sample was taken on the ground with the propellers of the multicopter UAV switched off and only the blower of the PCS being activated. The concentrations of the most frequently occurring pollen of the genera Corylus and Alnus were $23 \%$ lower than at the altitude of $25 \mathrm{~m}$ a.g.l. This might be an indication that sedimentation or filtration of the pollen grains by groundlevel vegetation leads to a depletion of the pollen concentration in near-ground air layers. Another possible explanation for this observation is that the inflow occurring at the air inlet of the PCS is increased due to the operation of the propellers of the multicopter UAV during aerial sampling, and thus the intake capture efficiency of the PCS might be increased, for example as a result of sub-isokinetic sampling conditions. If this is the case, and if this effect is reproducible, which requires further experiments, then such an increase in intake capture efficiency of the PCS could be used advantageously, since this would allow a further reduction in the sampling period necessary to collect a predetermined number of aerosol particles.

\subsubsection{Comparison to pollen forecast information services}

The Stiftung Deutscher Polleninformationsdienst (PID) publishes and stores online weekly forecasts (http://www.pollenstiftung.de/aktuelles/, last access: 7 March 2019) on the development of the pollen concentration in Germany, especially for pollen genera with a known allergy risk. The comparisons of the forecasts (http://www.pollenstiftung.de/aktuelleseinzelansicht/wochenpollenvorhersage-

stephan, http://www.pollenstiftung.de/aktuelles- 
einzelansicht/wochenpollenvorhersage-

angelika, http://www.pollenstiftung.de/aktuelleseinzelansicht/wochenpollenvorhersage-johanna, last access: 7 March 2019) with the values measured with the newly developed PCS on board the multicopter UAV are shown in Table 3. The pollen concentration of genus Taxus measured with the PCS rose over the 3 sampling days, for example at an altitude of $25 \mathrm{~m}$ a.g.l. from 11 to 68 pollen grains per $\mathrm{m}^{3}$. This is in agreement with the PID forecast, which also predicted a significant increase in the pollen concentration of Taxus for this period. The agreement of the PCS measurements with the PID forecasts is also reflected in other measured pollen concentrations such as the genera Corylus and Alnus. As predicted by the PID we also measured a significant decrease in the pollen concentrations from 18 to 2 (genus Corylus) and from 84 to 9 (genus Alnus). The good agreement between the forecasts of the PID and the results of the particle collection flights conducted in this study is a first strong indication that the newly developed PCS reliably determines the pollen concentration in ambient air, even when operated on board an airborne multicopter UAV.

The allergy centre of Switzerland (Allergiezentrum Schweiz) provides not only online forecast information on expected pollen concentration, but also on the actual daily pollen concentration (https://www.pollenundallergie.ch/infos-zu-pollen-und-

allergien/polleninformationen, last access: 7 March 2019). These accurate data are provided from a network of 14 measuring stations equipped with Burkard pollen traps (http://www.burkardscientific.co.uk/agronomics/hirst_

spore_sampler.htm, last access: 7 March 2019) that are operated by MeteoSwiss. For an evaluation (Table 3) of the pollen concentration values determined within our study, the measuring station of MeteoSwiss in Zürich was selected. The selection is based on the relatively short distance of about $130 \mathrm{~km}$ between Zürich and our measuring site in Poltringen, an almost identical altitude above sea level, and very similar temperature conditions during the measurement period (https://www.accuweather.com, last access: 7 March 2019). Figure 11 shows the comparison of the pollen concentrations of the genera Corylus and Alnus measured on 3,10, and 16 March with our PCS at an altitude of $25 \mathrm{~m}$ a.g.l. and by MeteoSwiss using Burkard pollen traps. On each of the 3 days, a generally slightly higher concentration of pollen of the genus Corylus was measured in Zürich than in Poltringen, but showed an almost parallel decreasing trend over the course of this period at both sites. In contrast, for pollen of the genus Alnus, a higher concentration was measured in Poltringen than in Zürich on each of the 3 days, but again showing an almost parallel decreasing trend towards the end of the sampling period. The slight differences in the absolute concentration values between the two sites might reflect the different dominating vegetation types in Poltringen and Zürich. In summary, it thus can be stated that the pollen concentration values determined during the measuring flights in Poltringen are in very good agreement with the corresponding pollen concentration values published by MeteoSwiss.

\section{Conclusions}

The presented multicopter-based UAS with the newly developed impactor-based particle collection system (PCS) operated in-flight and on board the multicopter UAV has proven to be a powerful and reliable system for aerosol particle collection in the ABL. More than 30 particle collection flights were carried out with this new UAS, each with a sampled air volume of $2 \mathrm{~m}^{3}$ and at flight altitudes of up to $300 \mathrm{~m}$ a.g.l.

A particle separation efficiency of more than $98 \%$ was determined for the newly developed impactor-based PCS despite the high airflow volume of $0.2 \mathrm{~m}^{3} \mathrm{~min}^{-1}$. In order to achieve a high particle capturing efficiency, the design and placement of the air inlet was optimized by conducting and evaluating visual airflow tests. Easily interchangeable sample carriers guarantee a lean post-flight workflow with regard to visual analysis using transmitted light microscopy. The use of a laminar airflow box reliably protects the particle sample carriers from particle contamination during their manufacturing, handling, and storing.

Subject to a sufficiently high concentration of the corresponding particles in the air, the number of in-flight collected particles was regularly well above 100 during a 10 min sampling operation. These large numbers of collected particles provide the possibility of reducing the volume of sampled air and thus reducing the aerial sampling period. Accordingly, particle collection flights at altitudes of up to $500 \mathrm{~m}$ a.g.l. and beyond are possible without any modification regarding the multicopter UAV.

The particle collection flights carried out during the pollen season in March 2017 at altitudes of $25 \mathrm{~m}, 100 \mathrm{~m}, 200 \mathrm{~m}$, and $300 \mathrm{~m}$ a.g.l. show remarkable vertical distribution of the various pollen genera and impressively illustrate the scientific potential of the newly developed PCS operated on board a multicopter UAV, such as the determination and modelling of the propagation behaviour of pollen, spores, and other airborne particles in the ABL (Aylor et al., 2006). In a more application-oriented context, it is very gratifying that the pollen concentration values measured with the new PCS on board the multicopter UAV match very well, both in their absolute numbers as well as in their relative temporal change, with the pollen concentration predictions and pollen concentration data published by the two pollen information services, Stiftung Deutscher Polleninformationsdienst (PID) and MeteoSwiss.

Data availability. The sample carriers of the particle collection operations are available for examination by interested parties. 
Competing interests. The authors declare that they have no conflict of interest.

Acknowledgements. This research was financed through institutional funding by Eberhard Karls Universität Tübingen. Martin Schön supported us in the manufacture of the bellmouth-shaped air inlet using FDM (fused depositing modelling) three-dimensional printing technology. In addition, we would like to express our gratitude to Barbara Maier, Simone Schafflick, and Wolfgang Kürner for their highly appreciated assistance in the implementation of numerous ideas into functional designs. In the realization of some technical solutions, we experienced kind support from companies established in the relevant technical fields; therefore we would like to express many thanks to Helmut Memmel and Alexander Post of the Daldrop + Dr. Ing. Huber GmbH \& Co. KG in 72666 Neckartailfingen, Germany for the provided insights into cleanroom technology and the generous provision of high efficiency air filter elements, Manuel Meier of the Sensirion AG in 8712 Stäfa, Switzerland for a kind introduction in air mass flow measuring and the provision of sensor samples, Julia Ganter of the ebm-Papst GmbH \& Co. KG in 78112 St. Georgen, Germany and Ernst Scherrer of the Micronel AG in 8317 Tagelswangen, Switzerland for the provision of miniature blower samples, and Jörg Haus and Rouven Möller of the Helmut Hund GmbH in 35580 Wetzlar, Germany as well as Matthias Werchan of Stiftung Deutscher Polleninformationsdienst for the provided insights into pollen and spores measurement and identification. Finally, we would also like to thank the editor and the anonymous reviewer for their kind and highly qualified comments, which have improved the quality of our manuscript.

Edited by: Francis Pope

Reviewed by: one anonymous referee

\section{References}

Aylor, D. E.: Quantifying maize pollen movement in a maize canopy, Agr. Forest Meteorol., 131, 247-256, 2005.

Aylor, D. E., Boehm, M. T., and Shields, E. J.: Quantifying aerial concentrations of maize pollen in the atmospheric surface layer using remote-piloted airplanes and Lagrangian stochastic modeling, J. Appl. Meteorol. Clim., 45, 1003-1015, https://doi.org/10.1175/JAM2381.1, 2006.

Aylor, D. E., Schmale, D. G., Shields, E. J., Newcomb, M., and Nappo, C. J.: Tracking the potato late blight pathogen in the atmosphere using unmanned aerial vehicles and Lagrangian modeling, Agr. Forest Meteorol., 151, 251-260, 2011.

Bastl, K., Berger, M., Bergmann, K.-C., Kmenta, M., and Berger, U.: The medical and scientific responsibility of pollen information services, Wien. Klin. Wochenschr., 129, 70-74, 2017.

Beug, H.-J.: Leitfaden der Pollenbestimmung für Mitteleuropa und angrenzende Gebiete, Verlag Dr. Friedrich Pfeil, 2004.

Boehm, M. T., Aylor, D. E., and Shields, E. J.: Maize pollen dispersal under convective conditions, J. Appl. Meteorol. Clim., 47, 291-307, 2008.

Brosy, C., Krampf, K., Zeeman, M., Wolf, B., Junkermann, W., Schäfer, K., Emeis, S., and Kunstmann, H.: Simulta- neous multicopter-based air sampling and sensing of meteorological variables, Atmos. Meas. Tech., 10, 2773-2784 https://doi.org/10.5194/amt-10-2773-2017, 2017.

Comtois, P., Fernández-González, D., Ma Valencia-Barrera, R., Sánchez, J. L., Fraile, R., and Rodier, S.: Pollen content study of the lower atmosphere in León (Spain) by use of a tethered balloon, Aerobiologia, 16, 187-191, 2000.

Damialis, A., Kaimakamis, E., Konoglou, M., Akritidis, I., TraidlHoffmann, C., and Gioulekas, D.: Estimating the abundance of airborne pollen and fungal spores at variable elevations using an aircraft: how high can they fly?, Sci. Rep.-UK, 7, 44535, https://doi.org/10.1038/srep44535, 2017.

Gottwald, T. R. and Tedders, W. L.: A spore and pollen trap for use on aerial remotely piloted vehicles, Phytopathology, 75, 801$807,1985$.

Griffiths, P., Borlace, J.-S., Gallimore, P., Kalberer, M., Herzog, M., and Pope, F.: Hygroscopic growth and cloud activation of pollen: a laboratory and modelling study, Atmos. Sci. Lett., 13, 289-295, 2012.

Haas, P., Balistreri, C., Pontelandolfo, P., Triscone, G., Pekoz, H., and Pignatiello, A.: Development of an unmanned aerial vehicle UAV for air quality measurements in urban areas, in: Proceedings of the 32nd AIAA Applied Aerodynamics Conference, American Institute of Aeronautics and Astronautics, Atlanta, GA, USA, 16-20, 2014

Hardin, P. J. and Hardin, T. J.: Small-scale remotely piloted vehicles in environmental research, Geography Compass, 4, 1297-1311, 2010.

Harrison, R. M. and Yin, J.: Particulate matter in the atmosphere: which particle properties are important for its effects on health? Sci. Total Environ., 249, 85-101, 2000.

Hassett, M. O., Fischer, M. W., and Money, N. P.: Mushrooms as rainmakers: how spores act as nuclei for raindrops, PloS one, 10 e0140407, https://doi.org/10.1371/journal.pone.0140407, 2015.

Hirst, J.: An automatic volumetric spore trap, Ann. Appl. Biol., 39, 257-265, 1952.

Hofmann, F., Ober, S., Janicke, L., Janicke, U., Kuhn, U., Schlechtriemen, U., Unselt, C., and Wittich, K.-P.: Eintrag von Maispflanzenteilen in die Umwelt: Abschätzung der Umweltexposition für die Risikobewertung transgener Pflanzen, Bundesamt für Naturschutz, 2013.

Hueglin, C., Gehrig, R., Baltensperger, U., Gysel, M., Monn, C., and Vonmont, H.: Chemical characterisation of $\mathrm{PM}_{2.5}, \mathrm{PM}_{10}$ and coarse particles at urban, near-city and rural sites in Switzerland, Atmos. Environ., 39, 637-651, 2005.

Jimenez-Sanchez, C., Hanlon, R., Aho, K. A., Powers, C., Morris, C. E., and Schmale III, D. G.: Diversity and ice nucleation activity of microorganisms collected with a small unmanned aircraft system (sUAS) in France and the United States, Front. Microbiol., 9, 1667, https://doi.org/10.3389/fmicb.2018.01667, 2018.

Kulkarni, P., Baron, P. A., and Willeke, K.: Aerosol measurement: principles, techniques, and applications, John Wiley \& Sons, 2011.

Lin, B., Ross, S. D., Prussin II, A. J., and Schmale III, D. G.: Seasonal associations and atmospheric transport distances of fungi in the genus Fusarium collected with unmanned aerial vehicles and ground-based sampling devices, Atmos. Environ., 94, 385391, 2014. 
Oteros, J., Pusch, G., Weichenmeier, I., Heimann, U., Möller, R., Röseler, S., Traidl-Hoffmann, C., Schmidt-Weber, C., and Buters, J. T.: Automatic and online pollen monitoring, Int. Arch. Aller. A. Imm., 167, 158-166, 2015.

Pope, F.: Pollen grains are efficient cloud condensation nuclei, Environ. Res. Lett., 5, 044015, https://doi.org/10.1088/17489326/5/4/044015, 2010.

Sassen, K., DeMott, P. J., Prospero, J. M., and Poellot, M. R.: Saharan dust storms and indirect aerosol effects on clouds: CRYSTAL-FACE results, Geophys. Res. Lett., 30, GL017371, https://doi.org/10.1029/2003, 2003.

Schmale, D., Ross, S., Fetters, T., Tallapragada, P., Wood-Jones, A., and Dingus, B.: Isolates of Fusarium graminearum collected 40320 meters above ground level cause Fusarium head blight in wheat and produce trichothecene mycotoxins, Aerobiologia, 28, 1-11, 2012.

Schmale III, D. G. and Ross, S. D.: Highways in the sky: Scales of atmospheric transport of plant pathogens, Annu. Rev. Phytopathol., 53, 591-611, https://doi.org/10.1146/annurev-phyto080614-115942, 2015.
Schmale III, D. G., Dingus, B. R., and Reinholtz, C.: Development and application of an autonomous unmanned aerial vehicle for precise aerobiological sampling above agricultural fields, J. Field Robot., 25, 133-147, 2008.

Shang, X., Li, X., An, Z., Ji, M., and Zhang, H.: Modern pollen rain in the Lake Qinghai basin, China, Sci. China Earth Sci., 52, 1510-1519, 2009.

Stull, R. B.: An introduction to boundary layer meteorology, vol. 13, Springer Science \& Business Media, 2012.

Vincent, J. H.: Aerosol sampling: science, standards, instrumentation and applications, John Wiley \& Sons, 2007.

Wildmann, N., Mauz, M., and Bange, J.: Two fast temperature sensors for probing of the atmospheric boundary layer using small remotely piloted aircraft (RPA), Atmos. Meas. Tech., 6, 21012113, https://doi.org/10.5194/amt-6-2101-2013, 2013. 